\title{
Analytical and Computational Indoor Shelter Models for Infiltration of Carbon Dioxide into Buildings: Comparison with Experimental Data
}

\author{
C.J. Lyons ${ }^{\mathrm{a}, \mathrm{c}}$, J.M. Race ${ }^{\mathrm{b}}$, K. Adefila ${ }^{\mathrm{b}}$, B. Wetenhall ${ }^{\mathrm{a}, 1}$, H. Aghajani ${ }^{\mathrm{a}}$, B. Aktas ${ }^{\mathrm{b}}$, H. F. Hopkins ${ }^{\mathrm{c}}$, \\ P. Cleaver ${ }^{\mathrm{d}}$ and J. Barnett $\mathrm{e}^{\mathrm{e}}$
}

${ }^{\text {a }}$ School of Engineering, Newcastle University, Armstrong Building, Queen Victoria Road, Newcastle-upon-Tyne, NE1 7RU, UK

${ }^{\mathrm{b}}$ Department of Naval Architecture, Ocean and Marine Engineering, University of Strathclyde, Henry Dyer Building, 100 Montrose Street, Glasgow, G4 0LZ, UK

${ }^{\mathrm{c}}$ Pipeline Integrity Engineers Ltd., 262A Chillingham Road, Heaton, Newcastle-upon-Tyne, NE6 5LQ, UK

${ }^{\mathrm{d}}$ Formerly with DNV-GL, Holywell Park, Ashby Road, Loughborough, Leicestershire, LE11 3GR, UK

${ }^{\mathrm{e}}$ National Grid, 35 Homer Road, Solihull, West Midlands, B91 3QJ, UK

\begin{abstract}
This paper describes two indoor shelter models - an analytical model and a Computational Fluid Dynamics (CFD) model - that can be used to predict the level of infiltration of carbon dioxide $\left(\mathrm{CO}_{2}\right)$ into a building following a release from an onshore $\mathrm{CO}_{2}$ pipeline. The motivation behind the development of these models was to demonstrate that the effects of shelter should be considered as part of a Quantitative Risk Assessment (QRA) for $\mathrm{CO}_{2}$ pipeline infrastructure and to provide a methodology for considering the impact of $\mathrm{a}_{2}$ release on building occupants.A key component in the consequence modelling of a release from a $\mathrm{CO}_{2}$ pipeline is an infiltration model for $\mathrm{CO}_{2}$ into buildings which can describe the impact on people inside buildings during a release event.

This paper describes the development of an analytical shelter model and a CFD model which are capable of predicting the change in internal concentration, temperature and toxic load within a single roomed building that is totally engulfed by a transient cloud of gaseous $\mathrm{CO}_{2}$. Application of the models is demonstrated by comparison with experimental measurements of $\mathrm{CO}_{2}$ accumulation in a building placed in the path of a drifting cloud of $\mathrm{CO}_{2}$. The analytical and CFD models are shown to make good predictions of the average change in internal concentration. Furthermore, it is demonstrated that the effects of shelter should be taken into account when conducting QRA assessments on $\mathrm{CO}_{2}$ pipelines.
\end{abstract}

\footnotetext{
${ }^{1}$ Corresponding author: Tel: (0044)191 2085532; E-mail: ben.wetenhall@ newcastle.ac.uk 
Keywords - $\mathrm{CO}_{2}$ pipelines; $\mathrm{CO}_{2}$ dispersion; Quantitative risk assessment; Consequence analysis; Shelter model

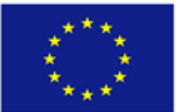

The Don Valley Power Project is co-financed by the European Union's European Energy Programme for Recovery The sole responsibility of this publication lies with the author.

The European Union is not responsible for any use that may be made of the information contained therein.

\section{INTRODUCTION}

The development and deployment of Carbon Capture and Storage (CCS) technologies have been recognised and accepted as one of the strategies that can be employed to reduce carbon dioxide $\left(\mathrm{CO}_{2}\right)$ emissions from fossil fuel fired processes such as coal and gas-fired power stations as well as industrial processes (such as steel making, fertiliser production and plastics manufacture). The International Energy Agency (IEA) has predicted that CCS strategies could enable the reduction of $\mathrm{CO}_{2}$ emissions by $14 \%$ by 2050 [1]. In a CCS scheme, $\mathrm{CO}_{2}$ is captured at a large stationary source and transported to a secure geological storage site either onshore or offshore. The selection of the mode of transportation for the $\mathrm{CO}_{2}$ is largely determined by the location of the capture plant and the storage sites (i.e. either onshore or offshore), the relative distance between the two and the quantities of $\mathrm{CO}_{2}$ to be transported. For onshore transportation, and for shorter distances offshore, pipelines are regarded as the most efficient and economical method for transporting $\mathrm{CO}_{2}$ from the capture facilities to destination storage sites [2].

In order to design and route onshore pipelines safely, it is important to be able to assess the risk to the public in an unlikely event of a pipeline failure. This requires the development of appropriate Quantitative Risk Assessment (QRA) procedures. A consistent level of safety is achieved along the pipeline route by defining safety distances around the pipeline based on the nature of the hazard. For natural gas pipelines, the safety distances are defined based on thermal hazards and the methodologies for conducting a QRA are well established. However, for $\mathrm{CO}_{2}$ pipelines, the hazard is toxic and therefore the safety distances need to be defined based on toxic loads rather than thermal loads.

$\mathrm{CO}_{2}$ is an asphyxiant in high concentrations but, in addition, has toxic effects above $\sim 4 \%$ by volume [2] (see [3] for a toxicological risk assessment review). Consequently, a rupture of a pipeline carrying $\mathrm{CO}_{2}$ could have severe consequences on the surrounding population if the risk is not managed appropriately. Due to the high density of $\mathrm{CO}_{2}$ in comparison with air, and depending on the specific environmental conditions at the time of the release, a significantly sized $\mathrm{CO}_{2}$ cloud could potentially be produced at ground level, thus increasing the probability that people could be affected by harmful concentrations.

In the event of a $\mathrm{CO}_{2}$ release, in addition to the people within buildings at the time of the release, people in the vicinity of the release may attempt to move away from the $\mathrm{CO}_{2}$ cloud generated, to seek shelter in nearby buildings. If the $\mathrm{CO}_{2}$ plume begins to enter the building through open windows, doors or via the adventitious openings characteristic of all buildings, the changing concentration of $\mathrm{CO}_{2}$ within the building is of critical importance to the safety of the people inside. If the release was constant and continuous, the concentration inside the building would eventually increase to match that of the external 
atmosphere. However, in the case of a decaying, transient release, such as could occur with a large pipeline rupture, the release rate decreases due to the reducing pressure and/or the closure of an isolation valve. Consequently the maximum concentration experienced indoors will be limited as a result of the effects of the decaying nature of the release. It is possible to simply analyse transient releases by using a representative steady state release rate, i.e. using a release rate at a specified period of time after the release has occurred. However, the selection of an appropriate release rate is at the discretion of the modeller. The adoption of an early time as a cautious approach (e.g. the rate at 30 seconds after the release) could result in an underestimate of risks close to the pipeline and an overestimate of the risk further away. Therefore it is more appropriate when conducting a QRA to use a transient calculation of the release rate and the corresponding variation of concentration with time in order that the time dependency of the concentration inside the building can be calculated.

The time required for the $\mathrm{CO}_{2}$ concentration to increase to harmful levels within the building could provide individuals taking shelter inside with additional time before a critical dose was received, increasing the chance of survival. It is therefore considered that the effects of shelter should be considered as part of a QRA for $\mathrm{CO}_{2}$ pipeline infrastructure. However, in order to be able to do this, appropriate shelter models need to be developed that can be used to predict the effect of $\mathrm{CO}_{2}$ exposure on building occupants during a release from an onshore $\mathrm{CO}_{2}$ pipeline. For this application, the shelter model needs to be able to take input data from dispersion models on external $\mathrm{CO}_{2}$ concentrations and temperature changes with time after a pipeline release event (for examples see [4-6]) and determine the changes in internal $\mathrm{CO}_{2}$ concentration and ambient temperature as the transient $\mathrm{CO}_{2}$ cloud engulfs and passes by a building. Furthermore, to find application in a QRA, such a shelter model must be computationally efficient, but produce sufficiently accurate results to allow a QRA to be conducted along a whole pipeline route within reasonable timescales and commensurate with the level of detail available on buildings along the proposed pipeline route and their ventilation mechanisms.

The primary motivation behind the study presented in this paper was to develop an analytical model that satisfied the above objectives, i.e. that could provide sufficiently accurate results in reasonable timescales and could be readily incorporated into the QRA process for onshore $\mathrm{CO}_{2}$ pipelines. A CFD model was also developed to provide a comparator for a range of conditions in the absence of experimental data. The analytical model, described in detail in Section 3, is based on principles of natural building ventilation [7], that have been extended to combine wind and buoyancy driven ventilation rates in the manner suggested by Etheridge and Sandberg $[8,9]$. The CFD model, described in detail in Section 4, utilises the Reynolds Averaged Navier-Stokes (RANS) equations with a buoyancy corrected $k-\epsilon$ turbulence model for compressible, multi-component flow to allow the treatment of transient uniform inlet and transient outlet boundary conditions.

In order to test the underlying theory behind the models, experimental measurements of $\mathrm{CO}_{2}$ accumulation in a building placed in the path of a drifting cloud of $\mathrm{CO}_{2}$ have been used as a comparison 
with the model outputs. The details of the experimental test and the modelling parameters are presented in Section 5 and Section 6 respectively. The comparison between the calculated change in $\mathrm{CO}_{2}$ concentration and temperature within the building and the experimental results is detailed in Section 7.

\section{MODELLING OF VENTILATION PROCESSES: LITERATURE REVIEW}

Building ventilation processes can be either naturally or mechanically driven. In this work the focus is on natural ventilation processes. Natural ventilation flows are principally driven by wind and buoyancy forces associated with the temperature and pressure difference between the fluid inside the building envelope and that of its surroundings [10]. Many models and methodologies have been published for the prediction of the ventilation performance of a building, primarily for the study of internal air quality as part of building design. Chen [11] has reviewed the most widely used approaches and has broadly grouped these models into seven categories; analytical models; empirical models; small-scale and fullscale experimental models; multi-zone and zonal models; and CFD models. The empirical models generally use experimental or CFD model results to develop coefficients relevant to particular applications of the analytical model. Chen [11] concluded that both analytical and empirical models are powerful and effective tools for predicting ventilation performance in buildings. It has further been demonstrated that analytical models can be applied to the problem of estimating the change in internal concentration due to the ingress of an external contaminant [12].

CFD is increasingly finding application in the study of a wide range of environmental and atmospheric processes. Full scale experiments usually take measurements at a limited number of points in space. CFD has the added advantage of providing estimations for all the points within the domain of study. Computational models describing natural ventilation of the indoor environment are well documented in the literature (e.g. [13-15] ). One approach is to simultaneously model the Atmospheric Boundary Layer $(\mathrm{ABL})$, wind flow and indoor fluid flow (mostly air) within the same computational domain. Utilisation of this method allows for a better representation of the flow field through and around openings in the building. However, it introduces a fairly large difference in geometrical length scales between the outdoor and indoor computational domains and therefore requires a large, high resolution grid [16]. There is a second approach, where the indoor and outdoor solution domains are decoupled. In this case, two separate simulations are carried out, one for the ABL wind flow and one for the indoor flow $[11,13,17,18]$. In [19] van Hooff and Blocken discuss the advantages and disadvantages of these two approaches in further detail for flows normal and parallel to openings. In the case of the current study, where infiltration of $\mathrm{CO}_{2}$ into a building is the primary objective of the research, the flow field data at the inlet(s) of the building are taken from experimental data or the output from dispersion models. Thus the interaction between wind flow and the ground is already accounted for in the inlet data.

\section{DEVELOPMENT OF THE ANALYTICAL MODEL}

The analytical model is based on theory relating to the determination of the pressure differences that arise in a building as a result of wind effects externally and/or buoyancy effects internally. Airflow between 
the internal and external atmospheres in the building occurs due to a pressure difference across the openings in the building envelope. Air will naturally flow from a region of higher pressure to a region of lower pressure. The pressure difference can arise as a result of wind effects externally and/or buoyancy effects internally. An illustration of ventilation airflow incorporating both of these effects is shown in Fig. 1 and Fig. 2, respectively. The theory behind the development of the analytical model is explained in the following sections.

\subsection{Wind Pressure}

Wind blowing against the surfaces of a building will cause an increase in the air pressure at those surfaces and any openings on those surfaces (Fig. 1). Conversely, the surfaces and openings of the building sheltered from the wind will experience a decrease in air pressure. The change in air pressure $P_{\text {wind }}$ due to the effect of the wind on a particular building surface is given by [8]:

$$
P_{\text {wind }}=\frac{1}{2} C_{s p} \rho_{\text {ext }} U_{\text {wind }}^{2}
$$

where $\rho_{\text {ext }}$ is the density of the external air, $U_{\text {wind }}$ is the wind speed and $C_{s p}$ is the surface pressure coefficient. The value of this coefficient depends upon the angle at which the wind impacts the surface and can be obtained from literature (e.g. (BS5925:1991) [7]).

\subsection{Buoyancy Pressure}

Pressure differences due to buoyancy arise as a result of a difference in temperature between the internal and external environments. Due to the principle of hydrostatics, atmospheric air pressure, $P$, decreases with increasing altitude. By taking the reference pressure $P_{r e f}$, at the top of the building, this can be represented using the following equation:

$$
P=P_{\text {ref }}+\rho g z
$$

Equation 2

where $\rho$ is the air density, $g$ is the acceleration due to gravity and $z$ is the distance from the top of the building. In the analytical model, the density of air in Equation 2 is obtained using the ideal gas equation:

$$
\rho=\frac{P}{R T}
$$

Equation 3

where $P$ is the air pressure, $R$ is the ideal gas constant and $T$ is the air temperature. This approximation is considered to be valid as the analysis is conducted in the far field (i.e. at atmospheric pressure), where the compressibility of air is approximately equal to unity.

If the building is open to the atmosphere and the internal atmosphere is at the same temperature as the external atmosphere then the internal and external pressure will be the same (assuming there is no wind) and will display an identical variation with height. From Equation 3, an increase in the internal air temperature will result in a reduction of the internal air density. As a result, the less dense air within the building will tend to rise. The internal air pressure is therefore increased from its initial value at the top 
of the building and decreased from its initial value at the bottom of the building. At some point within the building above ground level, there exists a plane in which the internal pressure equals that of the external pressure. This is the neutral pressure level which is shown in Fig. 2 and its position depends on the magnitude of the buoyancy pressure. Since air will flow from a high pressure to low pressure region, any openings in the envelope of the building below the neutral pressure level will therefore draw air in from the outside and any openings above the neutral pressure level will push air outside which sets up an air flow in the building as represented graphically in Fig. 2.

\subsection{Pressure Differences and Building Air Flow Rate}

Within the shelter model, pressure differences across the opening in the envelope of the building are calculated by combining the effects of wind and buoyancy. Combining Equation 1 and Equation 3 therefore yields the following expression for the total external air pressure $P_{\text {ext }}$ :

$$
P_{\text {ext }}=\frac{1}{2} C_{s p} \rho_{\text {ext }} U_{\text {wind }}^{2}+P_{\text {ref }}+\rho_{\text {ext }} g z \quad \text { Equation } 4
$$

Similarly, the corresponding equation for the internal air pressure on the same face at the same height, $P_{\text {int }}$, can be written as:

$$
P_{\text {int }}(z)=P_{\text {ref }}+P^{\prime}+\rho_{\text {int }} g z \quad \text { Equation } 5
$$

where $P^{\prime}$ is a pressure that is determined by the location of the zero pressure level (i.e. the difference between the internal and external pressure at the top of the building) and mass (or volume) conservation. In this case it is assumed that any changes in volume of the inflow caused by, for example, changes in internal pressure, are negligible and therefore mass conservation can be equated to volume concentration. The pressure difference across an opening in the envelope of the building at a height $z$ can therefore be calculated from the difference between Equation 4 and Equation 5 and is given by:

$$
\Delta P(z)=\frac{1}{2} C_{s p} \rho_{\text {ext }} U_{w i n d}^{2}-P^{\prime}+g z\left(\rho_{\text {ext }}-\rho_{\text {int }}\right)
$$

Equation 6

$P^{\prime}$ can be solved by assuming continuity of volume within the building, i.e. by assuming that the airflow into the building $\left(Q_{i n}\right)$ equals the airflow out of the building $\left(Q_{o u t}\right)$. The magnitude of the airflow across an opening at a height $z$ can be calculated using the following equation $[8,9]$ :

$$
Q(z)=C_{d} W(z) \sqrt{\frac{2|\Delta P|}{\rho}}
$$

where $C_{d}$ is the coefficient of discharge for the particular type of opening under consideration and may be obtained from literature [7], $W(z)$ is the width of the opening at height $z$ and $\rho$ is the internal or external air density.

If steady state flow through the room is assumed (i.e. $\left.Q_{\text {in }}=Q_{\text {out }}\right)$, then: 


$$
\int_{0}^{z_{0}} Q_{\text {in }}=\int_{z_{0}}^{h} Q_{\text {out }}
$$

where $h$ is the height of the building and $z_{o}$ is the height of the neutral pressure level at which it is known that:

$$
P_{\text {int }}\left(z_{0}\right)=P_{\text {ext }}\left(z_{0}\right)
$$

For the purposes of the analytical model, Equation 8 is approximated numerically using Simpson's Rule. In this section it has been shown how the rate of influx into and out of a building is dependent on the external and internal density of air. However, the density of air is affected by the composition of the air and the temperature. In order to be able to determine the effectiveness of a building in providing shelter in the event of a dense phase $\mathrm{CO}_{2}$ pipeline release, what needs to be considered is the effect of high external concentrations of $\mathrm{CO}_{2}$ and low air temperatures on the density of the air both inside and outside the building and to calculate the effect on the internal concentration of $\mathrm{CO}_{2}$. The incorporation of these effects into the analytical model is discussed in the next sections.

\subsection{Effect of $\mathrm{CO}_{2}$ Concentration and Temperature on Air Density}

\subsection{1 $\mathrm{CO}_{2}$ Concentration}

During the rupture of a dense phase $\mathrm{CO}_{2}$ pipeline, the air outside the building will contain a high external concentration of $\mathrm{CO}_{2}$ which changes with time as the release event evolves. As a result, the internal concentration of $\mathrm{CO}_{2}$ will also vary with time as more $\mathrm{CO}_{2}$ is drawn in from the outside due to the processes of ventilation discussed previously.

The internal and external air densities ( $\rho_{\text {int }}$ and $\rho_{\text {ext }}$ respectively) at any one time can be calculated by assuming an air/ $\mathrm{CO}_{2}$ mixture which behaves as an ideal gas²:

$$
\begin{gathered}
\rho_{\text {ext }}=\frac{P_{\text {ext }}}{R}\left[\frac{\left(1-C_{\text {ext }}\right) m_{\text {air }}+C_{\text {ext }} m_{C O_{2}}}{T_{\text {ext }}}\right] \\
\rho_{\text {int }}=\frac{P_{\text {int }}}{R}\left[\frac{\left(1-C_{\text {int }}\right) m_{\text {air }}+C_{\text {int }} m_{C O_{2}}}{T_{\text {int }}}\right]
\end{gathered}
$$

Equation 10

where $C_{\text {ext }}$ and $C_{i n t}$ are the external and internal volume concentrations respectively of $\mathrm{CO}_{2}$, and $m_{\mathrm{CO}_{2}}$ and $m_{\text {air }}$ are the molar masses of $\mathrm{CO}_{2}$ and air respectively. For the purpose of the analytical model, the internal and external pressures in Equation 10 and Equation 11 are assumed to be the same and equal to $P_{\text {ref. }}$

\footnotetext{
${ }^{2}$ At atmospheric pressure both the compressibility of air and $\mathrm{CO}_{2}$ are close to unity so this is a reasonable assumption.
} 
In the analytical model, Equation 8 is solved iteratively in order to determine the rate of air flow by ventilation into and out of the building at any instant in time. The air/ $/ \mathrm{CO}_{2}$ mixture from the outside drawn into the building is assumed to mix perfectly with the internal air/ $\mathrm{CO}_{2}$ causing the internal concentration of $\mathrm{CO}_{2}$ to change. The internal concentration of $\mathrm{CO}_{2}$ is calculated using the following method [20]:

The change in volume of $\mathrm{CO}_{2}$ flowing into the building in a time period $d t$ is:

$$
\Delta V_{C O_{2 i n}}=Q_{\text {in }} C_{\text {ext }} d t
$$

and the change in volume of $\mathrm{CO}_{2}$ flowing out of the building over $d t$ is:

$$
\Delta V_{\mathrm{CO}_{2} \text { out }}=Q_{\text {out }} C_{\text {int }} d t
$$

Therefore the total change in internal $\mathrm{CO}_{2}$ concentration over $d t$ is:

$$
d C_{\text {int }}(d t)=\frac{\left(\Delta V_{C_{2_{\text {in }}}}-\Delta V_{C O_{2} \text { out }}\right)}{V_{b}}
$$

Equation 14

where $V_{b}$ is the total volume of the building. The total internal concentration at a time $t+d t$ will therefore be:

$$
C_{\text {int }}(t+d t)=C_{\text {int }}(t)+d C_{\text {int }}(d t)
$$

Equation 15

As a result, given a changing external concentration of $\mathrm{CO}_{2}$ with time, it is possible, using this approach to calculate the change in internal concentration of $\mathrm{CO}_{2}$ with time.

The analytical model uses the same pressure equations as [21] for buoynacy and wind driven flow (Equation 1 and Equation 5). However, the two models differ in how they calculate the build up of pollutant inside the enclosures. In [21], concentration is determined using a Continuously Stirred Tank Reactor Model. Also, part of the venitilation calculations are not purely predictive and incorporate pressure test data. This method is not applicable for the case of $\mathrm{CO}_{2}$ ingress as it requires a series of pressure and flow measurements as calibration, which are not presently available.

One additional effect of the release of a cloud of $\mathrm{CO}_{2}$ that is considered in the analytical model is the effect on the ambient temperature, which in turn will affect the density of the $\mathrm{CO}_{2} /$ air mixture.

\subsubsection{Temperature Change}

Section 3.2 outlined the importance of internal and external temperature difference in establishing a ventilation flow rate due to buoyancy. $\mathrm{CO}_{2}$ vapour from a dense phase pipeline rupture can cool to temperatures of approximately $-80^{\circ} \mathrm{C}$ due to the Joule-Thomson effect [22]. A low vapour temperature such as this can change the temperature of the external environment surrounding the building and therefore affect its density and the ventilation flow rate. Furthermore, as external air is drawn into the building as the event progresses, the temperature of the internal environment will also be affected. These considerations are taken into account in the model by considering energy conservation. 
The change in enthalpy, $H$, of an ideal gas may be expressed as:

$$
d H=M C_{p} d T
$$

Equation 16

where $M$ is the mass of the gas, $C_{p}$ is the specific heat capacity (at constant pressure) and $T$ is the temperature of the gas. When considering the conservation of energy for air flow into and out of the building, the process is under constant pressure. Therefore the change in enthalpy within the building over a period of time $d t$ can be written in the following form, assuming that any inflow into the building due to changes in internal temperature can be ignored,

$$
\frac{d\left(M_{\text {int }} C_{p_{\text {int }}} T_{\text {int }}\right)}{d t}=\frac{d M_{\text {in }}}{d t} C_{p_{\text {in }}} T_{\text {ext }}-\frac{d M_{\text {out }}}{d t} \cdot C_{p_{\text {out }}} T_{\text {out }}
$$

Equation 17

where $M_{\text {int }}$ is the mass of air within the building, $M_{\text {in }}$ is the mass of air entering the building and $M_{\text {out }}$ is the mass of air leaving the building; $C_{p_{i n t}}$ is the specific heat capacity of the air within the building, $C_{p_{i n}}$ is the specific heat capacity of the air entering the building, $C_{p_{\text {out }}}$ is the specific heat capacity of the air leaving the building; and $T_{\text {int }}$ is the temperature of the air within the building, $T_{\text {ext }}$ is the temperature of the air entering the building and $T_{\text {out }}$ is the temperature of the air leaving the building. Expanding Equation 17 gives:

$$
\frac{d M_{\text {int }}}{d t} C_{p_{\text {int }}} T_{\text {int }}+\frac{d\left(C_{p_{\text {int }}} T_{\text {int }}\right)}{d t} M_{\text {int }}=\frac{d M_{\text {in }}}{d t} C_{p_{\text {in }}} T_{\text {ext }}-\frac{d M_{\text {out }}}{d t} \cdot C_{p_{\text {out }}} T_{\text {out }}
$$

Equation 18

Now the rate of change of mass inside the building is equal to the difference between the rate of change of mass entering and leaving the building, i.e. $\frac{d M_{\text {int }}}{d t}=\frac{d M_{\text {in }}}{d t}-\frac{d M_{\text {out }}}{d t}$, and therefore, by rearranging terms, Equation 18 becomes:

$$
\frac{d\left(C_{p_{\text {int }}} T_{\text {int }}\right)}{d t} M_{\text {int }}=\left(\frac{d M_{\text {in }}}{d t}\left(C_{p_{\text {int }}} T_{\text {ext }}-C_{p_{\text {int }}} T_{\text {int }}\right)\right)-\left(\frac{d M_{\text {out }}}{d t} \cdot\left(C_{p_{\text {out }}} T_{\text {out }}-C_{p_{\text {int }}} T_{\text {int }}\right)\right)
$$

Equation 19

If it is assumed that the air mixture inside the building is well mixed then $C_{p_{\text {int }}}=C_{p_{\text {out }}}$ and $T_{\text {out }}=T_{\text {int }}$, and Equation 19 becomes:

$$
\frac{d\left(C_{p_{\text {int }}} T_{\text {int }}\right)}{d t} M_{\text {int }}=\frac{d M_{\text {in }}}{d t}\left(C_{p_{\text {in }}} T_{\text {ext }}-C_{p_{\text {int }}} T_{\text {int }}\right)
$$

Now consider a mixture of $\mathrm{CO}_{2}$ and air entering the building. Assuming ideal gas behaviour the specific heat capacity of the mixture entering the building can be expressed as:

$$
C_{p_{\text {int }}}=\frac{\left(M_{\mathrm{CO}_{2}} C_{p_{\mathrm{CO}_{2}}}\right)+\left(M_{\text {air }} C_{p_{\text {air }}}\right)}{\left(M_{\text {air }}+M_{\mathrm{CO}_{2}}\right)}
$$


For the purposes of this assessment, it is sufficiently accurate to assume that $\mathrm{CO}_{2}$ and air have similar molar heat capacities and therefore $C_{p_{i n t}}$ can be considered to be constant. If it is further assumed that $C_{p_{\text {int }}}=C_{p_{\text {in }}}$ then Equation 20 can be simplified to give:

$$
\frac{d T_{\text {int }}}{d t} M_{\text {int }}=\frac{d M_{\text {in }}}{d t}\left(T_{\text {ext }}-T_{\text {int }}\right)
$$

Equation 22

$M_{\text {int }}$ can be calculated using:

$$
M_{\text {int }}=\rho_{\text {int }} \cdot V_{b}
$$

Equation 23

where $V_{b}$ is the volume of the building and $\rho_{\text {int }}$ may be calculated using Equation 11.

Additionally the mass of air entering the building may be expressed in terms of its density and volume:

$$
\frac{d M_{\text {in }}}{d t}=\rho_{\text {ext }} Q_{\text {in }}
$$

where $\rho_{e x t}$ is calculated using Equation 10 and $Q_{i n}$ is the ventilation flow rate as defined in Section 3.3. Using this methodology, the internal temperature change can be calculated over time.

Taking input for the concentration and temperature at the building openings (obtained from the output of a dispersion model or a set of experimental values), the analytical model then solves Equations 1 to 24 to give the average concentration of $\mathrm{CO}_{2}$ and air temperature within the building at each time step by iterating over $P^{\prime}$.

\section{DEVELOPMENT OF THE CFD MODEL}

To study the distribution of the $\mathrm{CO}_{2}$ stream within the building, the commercial CFD software STAR$\mathrm{CCM}+$ was used to develop a model for the prediction of $\mathrm{CO}_{2}$ infiltration inside a partially confined space [23]. The development of this model is discussed in the following section.

When $\mathrm{CO}_{2}$ is released from a pressurised pipeline, a high-speed two-phase jet may be formed. As the $\mathrm{CO}_{2}$ jet enters the atmosphere, it entrains ambient air into the jet stream which subsequently dilutes the $\mathrm{CO}_{2}$. The amount of air entrainment is determined by the turbulent motions generated by the $\mathrm{CO}_{2}$ jet. For the simulations in this study, the composition of the air inflow is assumed to be a multi-component gas mixture of air and $\mathrm{CO}_{2}$, i.e. the humidity of the air is neglected.

Analysis of the dispersion of $\mathrm{CO}_{2}$ from release events has indicated that the maximum deviation in the vicinity of the point of release from ideal gas conditions is less than $3 \%$ [24]. Consequently, the ideal gas law was adopted in the model for the prediction of fluid density based on temperature and pressure.

The governing equations of the CFD model are the continuity of mass, momentum and energy, which are given by Equations 25 to 27 respectively, as implemented in STAR-CCM [23]:

$$
\frac{\partial \rho}{\partial t}+\nabla \cdot(\rho v)=0
$$




$$
\begin{gathered}
\frac{\partial(\rho v)}{\partial t}+\nabla \cdot(\rho v \otimes v)=\nabla \cdot \sigma+f_{b} \\
\frac{\partial(\rho E)}{\partial t}+\nabla \cdot(\rho E v)=f_{b} \cdot v+\nabla \cdot(v \cdot \sigma)-\nabla \cdot q+S_{E}
\end{gathered}
$$

Where $\otimes$ denotes the Kronecker product, $v, h$, and $\sigma$ are velocity, specific enthalpy and the effective stress tensor respectively, $f_{b}$ is the resultant of the body forces (such as gravity and centrifugal forces) per unit volume acting on the continuum, $E$ is the total energy per unit mass, $q$ is the heat flux and $S_{E}$ is an energy source per unit volume.

The change in the internal concentration of $\mathrm{CO}_{2}$ within the building is modelled over the course of the rupture event. The air and $\mathrm{CO}_{2}$ mixture is treated as a single-phase pseudo-fluid (multi-component gas). The number of chemical species (in this case oxygen, nitrogen and $\mathrm{CO}_{2}$ ) is also conserved which can be expressed as:

$$
\frac{\partial \rho Y_{i}}{\partial t}+\nabla \cdot\left(\rho Y_{i} \boldsymbol{u}\right)=\nabla \cdot\left(\rho D \nabla Y_{i}\right), \text { for } i=1,2,3
$$

Equation 28

where $Y$ is the the species mass fraction, $D$ is the molecular diffusion coefficient and $i$ is the species.

Fluid flows can be simulated using various methodologies depending on the nature of the flow problem and the availability of computational resources. Numerical flow simulation methods can be broadly categorized into Reynolds Averaged Navier-Stokes (RANS), Detached Eddy Simulation (DES), Large Eddy Simulation (LES) and Direct Numerical Simulation (DNS) in increasing order of accuracy. The RANS methodology is widely used in the calculations of unsteady ventilation cases [13-15] and has been proven to provide sufficient accuracy for such simulations and hence has been utilised for the CFD model presented in this study. The standard $k-\epsilon$ turbulence model [25] was corrected to incorporate the effect of buoyancy driven flows with low Reynolds number. Four different variations of corrected $k-\epsilon$ turbulence models were tested against the experimental data (Section 5); the Lag Elipptic Blending (EB) $k-\epsilon$ model [26], V2F [27], EB [28] and Abe-Kondoh-Nagano (AKN) Low-Reynolds models [29, 30]. The Lag EB $k-\epsilon$ model provided the best comparison against the experimental data and has also been shown to provide superior predictive capability for unsteady flows in the literature [31]. Hence this model was selected for the infiltration model simulations. Instantaneous values of $k$ and $\epsilon$ for the chosen model are obtained from the transport equation for the four variables $k, \varepsilon, \varphi$, and $\alpha$ are [23]:

$$
\begin{array}{cr}
\frac{\partial}{\partial t}(\rho k)+\nabla \cdot(\rho k \bar{v})=\nabla \cdot\left[\left(\frac{\mu}{2}+\frac{\mu_{t}}{\sigma_{k}}\right) \nabla k\right]+G_{k}+G_{b}+Y_{M}-\rho\left(\varepsilon-\varepsilon_{0}\right)+S_{k} & \text { Equation } 29 \\
\frac{\partial}{\partial t}(\rho \varepsilon)+\nabla \cdot(\rho \varepsilon \bar{v})=\nabla \cdot\left[\left(\frac{\mu}{2}+\frac{\mu_{t}}{\sigma_{\varepsilon}}\right) \nabla \varepsilon\right]+\frac{1}{T_{e}} C_{\varepsilon 1}\left(G_{k}+C_{\varepsilon 3} G_{b}+\frac{1}{C_{\varepsilon 1}} E\right)-C_{\varepsilon 2}^{*}\left(\frac{\varepsilon}{T_{e}}-\frac{\varepsilon_{0}}{T_{0}}\right)+S_{\varepsilon} & \text { Equation } 30 \\
\frac{\partial}{\partial t}(\rho \varphi)+\nabla \cdot(\rho \varphi \bar{v})=\nabla \cdot\left[\left(\frac{\mu}{2}+\frac{\mu_{t}}{\sigma_{\varphi}}\right) \nabla \varphi\right]+P_{\varphi}+S_{\varphi} & \text { Equation } 31 \\
\nabla \cdot\left(L^{2} \nabla \alpha\right)=\alpha-1 & \text { Equation 32 }
\end{array}
$$




$$
\begin{gathered}
G_{k}=\mu_{t} S^{2}-\frac{2}{3} \rho k \nabla \cdot \overline{\mathrm{v}}-\frac{2}{3} \mu_{t}(\nabla \cdot \overline{\mathrm{v}})^{2} \\
G_{b}=\beta \frac{\mu_{t}}{\operatorname{Pr}_{t}}(\nabla \bar{T} \cdot \mathrm{g})
\end{gathered}
$$

where $\mu$ is the dynamic viscosity, $\bar{v}$ is the mean velocity, $C_{\varepsilon 1}, C_{\varepsilon 2}{ }^{*}, \sigma_{k}, \sigma_{\varepsilon}$, and $\sigma_{\varphi}$ are model coefficients, $G_{k}$ denotes the turbulent kinetic energy production, $G_{b}$ is the buoyancy production term and $\operatorname{Pr}_{t}$ is the turbulent Prandtl number.

\section{EXPERIMENTAL TEST SETUP}

The indoor shelter models developed in this study can be used to calculate the change in internal $\mathrm{CO}_{2}$ concentration and temperature with time for a single storey, single roomed building using input data to describe the change in external $\mathrm{CO}_{2}$ concentration and temperature with time. The structure used was a metal framed building, which was situated downwind from the source of a release. The majority of the openings that are normally present in the building were deliberately sealed for the experiment. However, two openings on opposite side walls were left open to provide a path for $\mathrm{CO}_{2}$ ingress and egress from the building. In order to test the underlying ideas behind the models, experimental measurements of $\mathrm{CO}_{2}$ accumulation within a building, placed in the path of the drifting cloud of $\mathrm{CO}_{2}$, have been made. The data was gathered during a $1 / 4$ scaled pipeline rupture experiment conducted by DNV GL at their Spadeadam facility as part of the National Grid COOLTRANS research programme [32]. The experimental setup including is described in detail in $[4,33]$ and as such is only relevant parts are summarised here.

The release was from a buried pipeline with external diameter $152 \mathrm{~mm}$ wall thickness $11 \mathrm{~mm}$. The pipeline was buried to a depth of $300 \mathrm{~mm}$ as measured from the top of the pipeline to the surface. The pipeline was initally at a pressure 136 bara and the release took place in a preformed crater which lasted a duration of 450 seconds. Locations of the instrumentation that was used to record the $\mathrm{CO}_{2}$ concentrations (sensors C1-C6) and temperatures (sensors T1-T6) at the inlet to the building, within the building and at the outlet of the building, are shown in Fig. 3. The concentration sensors and theromcouples used are identical to those used in [4, 32,,33]. Prior to the release, the building and ambient temperature were roughly $277 \mathrm{~K}$ and the ambient pressure was approximately 1 bara. Measurements began being taken $30 \mathrm{~s}$ prior to the release.

The building was situated $100 \mathrm{~m}$ downwind of the source of the release. The structure used was approximately $3.5 \mathrm{~m}$ by $3 \mathrm{~m}$ at the base and $3 \mathrm{~m}$ high and was constructed from sheet metal sides with a roof. The window on the upwind side was $1.04 \mathrm{~m}$ high by $0.24 \mathrm{~m}$ wide; and the window on the downwind side was $1.04 \mathrm{~m}$ high by $0.22 \mathrm{~m}$ wide. The height from the floor to the bottom of the windows was 1.3 $\mathrm{m}$.

It is highlighted that the dimensions of the openings used in the experiment were designed to represent the situation of a building with a small number of deliberate openings. Consequently the experimental 
setup does not represent a situation with adventitious ventilation only. The volume of the building used in the experiment is also much smaller than a domestic property and therefore the ventilation rate is larger than would be expected in a typical house. It was considered that this experimental design would allow internal accumulation of $\mathrm{CO}_{2}$ within the building to be measured within the timescales of the scaled experimental release. However, it is recognised that the internal accumulation of $\mathrm{CO}_{2}$ in the experiment would be much faster than would be expected within a domestic property.

Plots of the variation of inlet concentration (as measured by the upwind sensors C1 and C2) and temperature (as measured by the upwind sensors T1 and T2) against time are shown in Fig. 4a and Fig. 5 a respectively. These graphs indicate that the measurements made at the upper and lower levels of the inlet follow the same trends and have a similar magnitude. This suggests that the average of the upper and lower values provides a reasonable estimate of the concentration and temperature of the air/ $\mathrm{CO}_{2}$ mixture entering the building.

Measurements of the change of internal concentration (as measured by sensors C3 and C4) and temperature (as measured by sensors $\mathrm{T} 3$ and $\mathrm{T} 4$ ) over time were made at two different heights in the centre of the room and are shown in Fig. $4 \mathrm{~b}$ and Fig. $5 \mathrm{~b}$ respectively. Measurements of concentration and temperature over time were also taken at the outlet of the building (C5, C6, T5 and T6). These are presented in Fig. 4c and Fig. 5c. Looking at Figures 4 and 5, you can see the temperature drop as the cool cloud of $\mathrm{CO}_{2}$ passes and the corresponding rise in concentration. For each pair of concentration sensor (i.e. $\mathrm{C} 1 / \mathrm{C} 2, \mathrm{C} 3 / \mathrm{C} 4$ and $\mathrm{C} 5 / \mathrm{C} 6$ ), the concentration of the sensor that is physically lower tends to show a slightly higher concentration value of $\mathrm{CO}_{2}$. This is because the density of $\mathrm{CO}_{2}$ is greater than air so the density of the $\mathrm{CO}_{2}$ cloud tends to increase with decreasing height (although it is noted this could change depending on the degree of turbulence present). It is highlighted that the internal concentrations (C3 and $\mathrm{C} 4)$ and the concentrations at the outlet (C5 and C6) are similar suggesting that the perfect mixing approximation assumed in the infiltration models is reasonable.

The temporal variations in wind speed at elevations of $5 \mathrm{~m}$ and $10 \mathrm{~m}$ above the ground, upstream of the release and in the vicinity of the building are presented in Fig. 6. The second concentration peak in Fig. 4 seems to coincide with the large increase in wind speed seen around $1000 \mathrm{~s}$.

\section{MODELLING ASSUMPTIONS AND COMPUTATIONAL SETUP}

Sections 3 and 4 have described the development of two models which, using input from dispersion data or a dispersion model, can predict the changes in internal $\mathrm{CO}_{2}$ concentration and temperature as a cloud of gaseous $\mathrm{CO}_{2}$ drifts past and engulfs a building. In order to validate the principles behind the models, a comparison has been made between the model predictions of internal $\mathrm{CO}_{2}$ concentration and temperature and the measurements recorded within a building during an experimental release. This section describes the assumptions made and computational setup used within the models to simulate the experimental test. 
As two readings for $\mathrm{CO}_{2}$ concentration and temperature were measured at the inlet to the building during the experiment (Fig. 4a and Fig. 5a), the values of concentration and temperature used by the models were taken as the average of these readings at a particular time step. This data is then used as input by the models to calculate the quantity of $\mathrm{CO}_{2}$ entering and leaving the building and the change in internal temperature over time. Only the readings made at integer values of time (1 s, $2 \mathrm{~s}, 3 \mathrm{~s}$ etc.) were used to reduce the processing time..

For both models, the initial internal temperature in the building was assumed to be the same as the initial external temperature $(287 \mathrm{~K})$ and the initial $\mathrm{CO}_{2}$ concentration in the building was assumed to be the atmospheric background level of $0.039 \%[34]^{3}$. The wind speed was a constant value taken to be the average of the experimental readings $(1.17 \mathrm{~m} / \mathrm{s})$ and assumed to be incident on the opening.

\subsection{Analytical Model}

The analytical model has been designed using the openings in a simple building as depicted in BS5925:1991[7] and illustrated in Fig. 1, with two openings on the front and rear walls of the building separated by a vertical distance. In order to represent the building used in the experiment in the analytical model, the single rectangular openings of the test building were replaced with two closely spaced square windows on the front and rear walls of the model. The windows were spaced with a vertical gap of 0.04 $\mathrm{m}$ between them. In the analytical model, the windows are identically sized, unlike those in the experimental test case. However, the window area in the shelter model has been selected such that the total window area on the upwind face is identical to that of the test building.

The concentration of $\mathrm{CO}_{2}$ within the interior is assumed to be uniform. This assumption is considered to be reasonable for single storey buildings in which the openings are large enough to allow a significant inflow of $\mathrm{CO}_{2}$.

The front and back face pressure coefficients, $C_{s p f}$ and $C_{s p b}$ in Equation 1 and the window discharge coefficient $C_{d}$ in Equation 7, were assumed to be $0.7,-0.25$ and 0.61 respectively [7], where the subscripts $f$ and $b$ correspond to the front and back faces of the building respectively.

\subsection{CFD Model}

A Computer Aided Design (CAD) model used for the computational domain is shown in Fig. 7. The CAD model was explicitly built based on the building dimesions described in Section 5 and are thus identical to the experimental setup. The CAD model was converted to an Initial Graphics Exchange Specification (IGES) format to enable import into the CFD environment. The imported CAD model was meshed within STAR-CCM+ using the automatic meshing facility. A polyhedral mesher was employed to produce a high-quality grid within the solution domain and a prism layer mesher was used to improve the CFD simulation in the near-wall regions. For the mesh convergence study, three different meshes

\footnotetext{
${ }^{3}$ Ten-year average of $\mathrm{CO}_{2}$ annual mean atmospheric concentration data (2005-2014) measured at Mauna Loa Observatory, Hawaii.
} 
were generated; coarse, medium and fine mesh with 45,000, 110,000 and 300,000 number of cells respectively. Overall, no significant improvement was observed with the utilisation of either the fine or the medium mesh. Therefore the coarse mesh was chosen for the domain modelling.

The walls, celling and floor were modelled as smooth wall boundaries where the no-slip condition is applied. The pressure at the oultet is assumed to be atmospheric pressure meaing that the need to specify the full wind profile upstream of the building is negated. The flow is incompressible and the ideal gas law is used to approximate the density as the compressibility of the $\mathrm{CO}_{2} /$ air mixture is very close to one. It is assumed that there is no heat flux between the walls and the fluid. The initial turbulence, which may have existed within the building due to natural convection, was ignored.

The time-step convergence study was conducted with three solutions based on the Courant-FriedrichsLewy (CFL) condition [35]. For this purpose, the Convective Courant number option offered by STAR$\mathrm{CCM}+$ was utlised. This option enables the determination of a target mean and maximum CFL number over the whole computational domain. Three simulations were conducted with mean CFL numbers corresponding to 1,5 and 10 . The results indicated that there was no signifcant difference between the output predictions determined using CFL numbers of 1 or 5 . Hence, the simulation was set up using a mean CFL number of 5 with a maximum target CFL number of 10 over the whole computational domain.

In the present work, the flow is transient but it experiences limited velocity changes over the whole domain. However, the use of a variable time-step ensures that the largest reasonable time-step is used at each iteration. These time steps are determined based on the above conducted time-step convergence study.

\section{RESULTS AND DISCUSSION}

In a comparison with the experimental results, the CFD model has the advantage over the analytical model in that, by designing the mesh appropriately, it is possible to make exact predictions at the sensor locations used in the experiment. By contrast, the output of the analytical model output represents the change in the average concentration within the building. Consequently the comparison of the model outputs with the experimental data are presented in two sections; comparison of the CFD output with the experimental data at the sensor locations (Section 7.1) and comparison of the averaged CFD results and experimental data at the sensor locations with the output of the analytical model (Section 7.2).

\subsection{Predictions of CFD Model at Sensor Locations}

\subsubsection{Internal $\mathrm{CO}_{2}$ concentration at Sensor Locations}

Fig. 8 shows the comparison between the experimental measurements and the CFD predictions of concentration for the sensors located within the centre of the building (C3 and $\mathrm{C} 4)$. For both locations, the form of the experimental measurements is replicated, showing an intial peak around 500 seconds and 
a secondary peak between 800-1000 seconds. For the sensor located at the bottom of the building (C3), the CFD overpredicts the concentration with a maximum offset at the peak location of $3.5 \% \mathrm{CO}_{2}$ concentration, whilst at sensor $\mathrm{C} 4$ the maximum concentration is under predicted by $1.0 \% \mathrm{CO}_{2}$ concentration with a small offset in the time taken to reach the peak concentration compared with the experimental measurements.

The predictions of $\mathrm{CO}_{2}$ concentration at the outlet of the building are shown in Fig. 9. As can be seen, the CFD model overestimates the maximum $\mathrm{CO}_{2}$ concentrations at both sensors (C5 and C6). At $\mathrm{C} 6$ (the upper sensor) the concentration profile is overpredicted by a maximum concentration of $2.0 \% \mathrm{CO}_{2}$ concentration at around 900 seconds. However, at C5, the whole profile shows close agreement with experimental data with only the peak overpredicted by a concentration of $2.6 \% \mathrm{CO}_{2}$ concentration.

\subsubsection{Internal Temperature at Sensor Locations}

Fig. 10 shows the comparison between the experimental measurements and the CFD predictions of temperature at sensors $\mathrm{T} 3$ and $\mathrm{T} 4 \mathrm{in}$ the centre of the building. As with the $\mathrm{CO}_{2}$ concentration predictions described in Section 7.1.1, the general form of the temperature profile is predicted by the CFD model at both temperature sensors. The model underpredicts the minimum temperature by $7.0 \mathrm{~K}$ at $\mathrm{T} 3$ and overpredicts the minimum temperature by $2.0 \mathrm{~K}$ at $\mathrm{T} 4$. However, after the minimum point, the deviation over the rest of the profile at $\mathrm{T} 4$ is less than $1 \mathrm{~K}$.

The predictions of temperature at the outlet of the building (T5 and T6) are shown in Fig. 11. At both these sensor locations, the CFD model overpredicts the minimum temperature by $7.0 \mathrm{~K}$ at $\mathrm{T} 5$ and $4.4 \mathrm{~K}$ at T6. However, after the minimum temperature location, 500 seconds after the release, the deviation is less than $1 \mathrm{~K}$ on average.

The temperature predictions are deemed acceptable since the the focus of the work is on predicting the cocnetration and the associated risk. Furthermore, there is some uncertainty around the experimental temperature measurments as the temperature sensors used to collect the data are accurate to within $5 \mathrm{~K}$ at worst [4]. Temperature predictions of the CFD model could be improved by including the heat transfer between the fluid and walls and by adding a roughness value for the walls.

\subsection{Predictions of Models with Averaged Data}

As detailed previously, the output from the analytical model is the average $\mathrm{CO}_{2}$ concentration and temperature within the building. Consequently, in order to compare the predictions of the analytical model with the experimental results and CFD predictions, the data at the two sensor locations C3 and C4 and $\mathrm{T} 3$ and $\mathrm{T} 4$ have been averaged.

\subsubsection{Average Internal $\mathrm{CO}_{2}$ Concentration}


A comparison between the average values of the internal $\mathrm{CO}_{2}$ concentration predicted using the analytical shelter model, the CFD model and the data recorded during the experimental test case is shown in Fig. 12. From this figure it can be seen that the CFD model predicts the initial build up of $\mathrm{CO}_{2}$ within the builidng more accurately than the analytical model. However, the analytical model predicts the peak concentration within $0.1 \% \mathrm{CO}_{2}$ concentration of the experimental data wheras the CFD model is overpredicting the peak by $0.84 \% \mathrm{CO}_{2}$ concentration. After the peak concentration, the two models predict a slower decay in the $\mathrm{CO}_{2}$ concentration than observed in the experiment. It is interesting to note that the concentration predictions for the CFD and analytical models converge after 2500 seconds at $1.6 \%$ although the experimental concentration average after 1500 seconds is $0.63 \%$.

\subsubsection{Average Internal Temperature}

Fig. 13 shows the comparison between the average internal temperature measured within the building with the predictions of the CFD and analytical models. Both models follow the general form of the experimental data but they overpredict the minimum temperature within the building by $1.3 \mathrm{~K}$ for the analytical model and $2.5 \mathrm{~K}$ for the CFD model. However, all models converge after 3200 seconds to the background temperature of $276 \mathrm{~K}$.

\subsection{Comparison of toxic dose}

Although the comparison of internal $\mathrm{CO}_{2}$ concentration and internal temperature is informative, it is more revealing, from a risk perspective, to quantify and study the impact of the toxic dose the people inside the building will receive. The toxic dose, as formulated in Equation 35, is a cumulative quantity that increases over time, meaning that the duration of the exposure to $\mathrm{CO}_{2}$ is as important as the value of the concentration.

$$
D=\int c(t)^{n} d t
$$

Equation 35

In Equation 35, $c(t)$ is the concentration of the contaminant a person is exposed to in parts per million $(\mathrm{ppm})$, and $t$ is the time of the exposure. $n$ is the toxic index which can take different values depending on the nature of the contaminant. For $\mathrm{CO}_{2}$ the Health and Safety Executive (HSE) specify a value of $n$ $=8$ [36]. Dangerous Toxic Loads (DTL) are values of dose specified by the HSE which represent harmful levels of exposure to a contaminant [36]. Two dose levels are defined; Specified Level of Toxicity (SLOT) and Significant Likelihood of Death (SLOD). For an average population exposed to the SLOD dose, $50 \%$ of people would be expected to become a fatality. For $\mathrm{CO}_{2}$, the SLOT dose is $1.5 \times 10^{40}$ $\mathrm{ppm}^{8} \mathrm{~min}$ and the SLOD is $1.5 \times 10^{41} \mathrm{ppm}^{8} \mathrm{~min}$. There is some dispute around the values of the SLOT and SLOD dosages which could in fact be lower than stated here [37]. However, the values quoted here from [36] are used for illustration.

In Fig. 14, the CFD predictions and the experimentally measured $\mathrm{CO}_{2}$ concentrations at the internal sensors $\mathrm{C} 3$ and $\mathrm{C} 4$ have been averaged and used to calculate the toxic dose, which is then compared 
against the internal toxic dose obtained from the analytical shelter model. It can be seen that the CFD model overpredicts the toxic dose throughout the simulation time. However, the analytical shelter model underpredicts the toxic dose received in the first 500 seconds but subsequently matches the experimental data closely, predicting an ultimate toxic dose of $8.3 \times 10^{38}$ compared with $7.62 \times 10^{38}$ calculated from the experimental data. It should be noted however that neither the SLOT nor the SLOD dose is reached inside the building during the experiment.

The reason that the predictions of toxic load from the analytical model are closer to the experimentally determined values than those of the CFD model can be understood by inspection of the concentration charts in Fig. 12. The CFD model overpredicts the $\mathrm{CO}_{2}$ concentration for the majority of the simualation whereas the analytical model underpredicts the experimental data for the first 500 seconds and then overpredicts the data. As the toxic dose is a function of the concentration raised to the power of 8 (Equation 35), the difference in the CFD model predictions are accumulated, whilst the differences in the analytical model cancel each other out to some extent.

For comparison, the toxic dose has also been calculated using the concentrations measured at the inlet to the building ( $\mathrm{C} 1$ and $\mathrm{C} 2)$ and compared with the toxic dose calculated using the average of the internal sensors ( $\mathrm{C} 3$ and $\mathrm{C} 4)$ in Fig. 15. In this case the SLOT dose is reached at the inlet to the building after 375 seconds although the SLOD dose is never achieved. This raises an important point with respect to the use of shelter models within QRA procedures. If the observed incoming dose was used to predict the outcome for people inside the building, then a different assessment of the consequences would have been achieved. It has therefore been demonstrated by the models described in this paper that, during the release event, the building would have provided adequate shelter ${ }^{4}$. There are therefore plausible cases in which the application of a shelter model would make a difference in the risk assessment outcome if the alternative is to use the observed external concentration at a particular location to calculate the dose.

\section{CONCLUSIONS}

This paper has described the development of two models - an analytical and a CFD model - that can be used to predict the change in internal $\mathrm{CO}_{2}$ concentration and temperature during an event where a single roomed building is totally engulfed by a dispersing cloud of gaseous $\mathrm{CO}_{2}$. The underlying principles behind the analytical and CFD models have been successfully tested against data collected within a building during an experimental release of $\mathrm{CO}_{2}$ under high ventilation rate conditions.

The comparison of the predictions of the models with the experimental data indicates that the CFD model tends to overpredict the measured concentration data, which leads to an overprediction of the toxic dose received by an individual in a building. It is highlighted that this would be conservative in a QRA assessment. It is considered that the differences between the errors in the CFD predictions could have arisen from some of the assumptions that had to be made in the model setup due to lack of experimental

${ }^{4}$ However, it is important to note that SLOD may be reached for a longer release. 
measurements. For example, the wind speed data was only available in the vicinity of the building at distances of $5 \mathrm{~m}$ and $10 \mathrm{~m}$ above the ground although the inlet to the building was $1.3 \mathrm{~m}$ above the ground.

The analytical model was better able to predict the average change in internal concentration with time and therefore more accurately predicted the toxic dose in the building when compared with an average of the experimental data.

It has further been demonstrated that, for the experimental case considered, the dose received by an individual in the building, calculated using both the analytical and the CFD models, would not reach the levels of toxicity calculated in the situation where the effects of shelter are not considered. It is therefore recommended that the effects of shelter are taken into account when conducting QRA assessments on $\mathrm{CO}_{2}$ pipelines.

The models presented here could find application in allowing the effect of shelter to be considered in a QRA. In particular the analytical model is computationally efficient and allows results to be generated quickly along a proposed pipeline route. For particularly high risk areas, where it is possible to gather more data on the environmental conditions and the building geometry, further detailed study could be made using the CFD approach.

It is highlighted that the $\mathrm{CO}_{2}$ cloud in the analysis was assumed to completely envelope the openings in the building and it is important that future work examines the effects of conditions in which the clouds only cover a fraction of the building's openings. The introduction of partitions within the building to simulate different rooms and the effect of ventilation rate on the predictions are also areas of development for the models to extend the applicability of the approach.

\section{ACKNOWLEDGEMENTS}

This work has been funded by the UK Carbon Capture and Storage Research Centre (UKCCSRC) within the framework of the S-Cape project (UKCCSRC-C2-179) and the National Grid COOLTRANS research programme and the authors would like to acknowledge the financial support of National Grid and the UKCCSRC in carrying out this research. The authors would also like to thank National Grid and DNV-GL for the provision of the experimental input data for the validation study and Dr Enrong Chang for his assistance. The UKCCSRC is supported by the EPSRC as part of the Research Councils UK Energy Programme under grant EP/K000446/1. Data supporting this research are openly available from www.bgs.ac.uk/ukccs under project 19851404.

\section{REFERENCES}

[1] IEA, Technology Roadmap: Carbon Capture and Storage - 2013 edition, in, International Energy Agency, 2013. [2] IPCC, IPCC Special Report on Carbon Dioxide Capture and Storage, in: B. Metz, O. Davidson, H.C. de Coninck, M. Loos, L.A. Meyer (Eds.) Working Group III of the Intergovernmental Panel on Climate Change, Cambridge University Press, Cambridge, United Kingdom, 2005.

[3] M. Hillebranda, S. Pflugmacher, A. Hahn, Toxicological risk assessment in $\mathrm{CO}_{2}$ capture and storage technology, International Journal of Greenhouse Gas Control 55 (2016) 118-143. 
[4] C.J. Wareing, M. Fairweather, S.A.E.G. Falle, R.M. Woolley, Modelling ruptures of buried high pressure dense phase $\mathrm{CO}_{2}$ pipelines in carbon capture and storage applications - Part I. Validation, International Journal of Greenhouse Gas Control 42 (2015) 701-711.

[5] X. Liu, A. Godbole, C. Lu, G. Michal, Investigation of terrain effects on the consequence distance of $\mathrm{CO}_{2}$ released from high-pressure pipelines, International Journal of Greenhouse Gas Control 66 (2017) $264-275$.

[6] X. Liu, A. Godbole, C. Lu, G. Michal, V. Linton, Investigation of the consequence of high-pressure $\mathrm{CO}_{2}$ pipeline failure through experimental and numerical studies, Applied Energy 250 (2019) 32-47.

[7] BS5925, BS5925:1991, in: Code of Practice for Ventilation Principles and Designing for Natural Ventilation, British Standards Institute, London, 1991.

[8] D.W. Etheridge, M. Sandberg, A simple parametric study of ventilation, Build. Environ., 19 (1984) 163-173.

[9] D.W. Etheridge, M. Sandberg, Building Ventilation: Theory and Measurement, New York: John Wiley and Sons, 1996.

[10] G.R. Hunt, P.F. Linden, The fluid mechanics of natural ventilation - Displacement ventilation by buoyancydriven flows assisted by wind, Build. Environ., 34 (1999) 707-720.

[11] Q. Chen, Ventilation performance prediction for buildings: A method overview and recent applications, Build. Environ., 44 (2009) 848-858.

[12] C.H. Halios, C.G. Helmis, On the estimation of characteristic indoor air quality parameters using analytical and numerical methods, Science of The Total Environment, 381 (2007) 222-232.

[13] T. Van Hooff, B. Blocken, CFD evaluation of natural ventilation of indoor environments by the concentration decay method: CO2 gas dispersion from a semi-enclosed stadium, Build. Environ., 61 (2013) 1-17.

[14] B. Blocken, T. Stathopoulos, J. Carmeliet, J.L.M. Hensen, Application of computational fluid dynamics in building performance simulation for the outdoor environment: An overview, J. Build. Perform. Simul., 4 (2011) 157-184.

[15] R. Yoshie, A. Mochida, Y. Tominaga, H. Kataoka, K. Harimoto, T. Nozu, T. Shirasawa, Cooperative project for CFD prediction of pedestrian wind environment in the Architectural Institute of Japan, J. Wind Eng. Ind. Aerodyn., 95 (2007) 1551-1578.

[16] T. van Hooff, B. Blocken, L. Aanen, B. Bronsema, A venturi-shaped roof for wind-induced natural ventilation of buildings: Wind tunnel and CFD evaluation of different design configurations, Build. Environ., 46 (2011) 1797 1807.

[17] M.J. Cook, Y. Ji, G.R. Hunt, CFD Modelling of Natural Ventilation: Combined Wind and Buoyancy Forces, International Journal of Ventilation, 1 (2003) 169-179.

[18] Y. Jiang, Q. Chen, Effect of fluctuating wind direction on cross natural ventilation in buildings from large eddy simulation, Build. Environ., 37 (2002) 379-386.

[19] T. van Hooff, B. Blocken, Full-scale measurements of indoor environmental conditions and natural ventilation in a large semi-enclosed stadium: Possibilities and limitations for CFD validation, J. Wind Eng. Ind. Aerodyn., 104106 (2012) 330-341.

[20] R.J. Harris, The Investigation and Control of Gas Explosions in Buildings and Heating Plant, E \& F Spon Ltd, British Gas Corporation, 1983.

[21] Health \& Safety Executive, Modelling smoke and gas ingress into offshore temporary refuges, Research Report RR997, 2013.

[22] W. Zheng, H. Mahgerefteh, S. Brown, S. Martynov, Integral multiphase turbulence compressible jet expansion model for accidental releases from pressurized containments, Ind. Eng. Chem. Res., 55 (2016) 7558-7568.

[23] S.P. Software, STAR-CCM+ in, 2016.

[24] J. Wen, A. Heidari, B. Xu, H. Jie, Dispersion of carbon dioxide from vertical vent and horizontal releases-A numerical study, Proc. Inst. Mech. Eng. Part E J. Process Mech. Eng., 227 (2013) 125-139.

[25] B.E. Launder, B.I. Sharma, Application of the energy-dissipation model of turbulence to the calculation of flow near a spinning disc, Letters in Heat and Mass Transfer, 1 (1974) 131-137.

[26] A.J. Revell, S. Benhamadouche, T. Craft, D. Laurence, A stress-strain lag Eddy viscosity model for unsteady mean flow, International Journal of Heat and Fluid Flow, 27 (2006) 821-830.

[27] F.S. Lien, G. Kalitzin, P.A. Durbin, RANS modeling for compressible and transitional flows, in: Centre for Turbulence Research, Proceedings of the Summer Program, 1998, pp. 267-285.

[28] R. Manceau, K. Hanjalić, Elliptic blending model: A new near-wall Reynolds-stress turbulence closure, Phys. Fluids, 14 (2002) 744-754.

[29] K. Abe, T. Kondoh, Y. Nagano, A new turbulence model for predicting fluid flow and heat transfer in separating and reattaching flows-I. Flow field calculations, Int. J. Heat Mass Transf., 37 (1994) 139-151.

[30] K. Abe, T. Kondoh, Y. Nagano, A new turbulence model for predicting fluid flow and heat transfer in separating and reattaching flows-II. Thermal field calculations, Int. J. Heat Mass Transf., 38 (1995) 1467-1481.

[31] S. Lardeau, F. Billard, Development of an elliptic-blending lag model for industrial applications, in: 54th AIAA Aerospace Sciences Meeting, San Diego, California, USA, 2016. 
[32] D. Allason, K. Armstrong, J. Barnett, P. Cleaver, A. Halford, Experimental studies of the behaviour of pressurised releases of carbon dioxide, in: 23rd Institution of Chemical Engineers Symposium on Hazards, Southport, 2012, pp. 142-152.

[33] D. Allason, K. Armstrong, J. Barnett, P. Cleaver, A. Halford, Behaviour of releases of carbon dioxide from pipelines and vents, 10th Int. Pipeline Conf. America Society of Mechanical Engineers, Calgary Alberta, Canada (2014).

[34] P. Tans, R. Keeling, Mauna Loa $\mathrm{CO}_{2}$ annual mean data - NOAA/ESRL and Scripps Institution of Oceanography, in, www.esrl.noaa.gov/gmd/ccgg/trends/ and www.scrippsco2.ucsd.edu/ 2015.

[35] R. Courant, K. Friedrichs, H. Lewy, On the Partial Difference Equations of Mathematical Physics, IBM Journal of Research and Development, 11 (1967) 215-234.

[36] Health \& Safety Executive, Toxicity levels of chemicals: Assessment of the Dangerous Toxic Load (DTL) for Specified Level of Toxicity (SLOT) and Significant Likelihood of Death (SLOD), in, 2015.

[37] I.J. Duncan, Re-evaluating $\mathrm{CO}_{2}$ toxicity and lethality: implications for risk assessments of carbon capture and storage (CCS). In: Duncan: Developing a Comprehensive Risk Assessment Framework for Geological Storage of $\mathrm{CO}_{2}$. Report for the U.S. Department of Energy (DOE Award Number:DE-FE0001563), 2014. 


\section{FIGURES}

\section{Outside}

Incident Wind
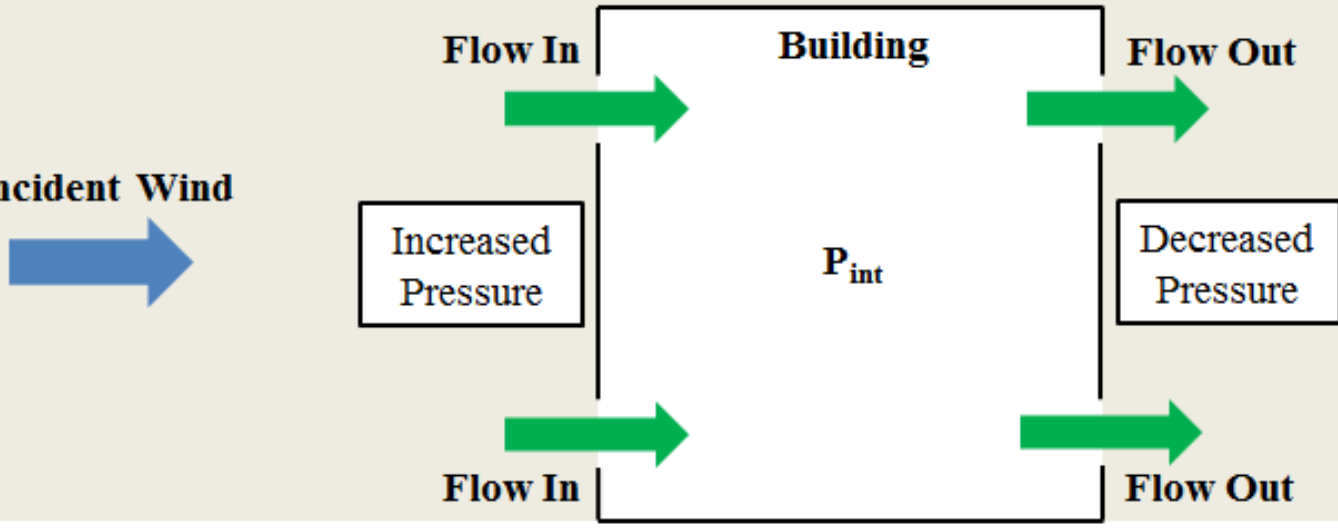

Fig. 1: Schematic representation of pressure differences due to wind driven effects.

\section{Outside}

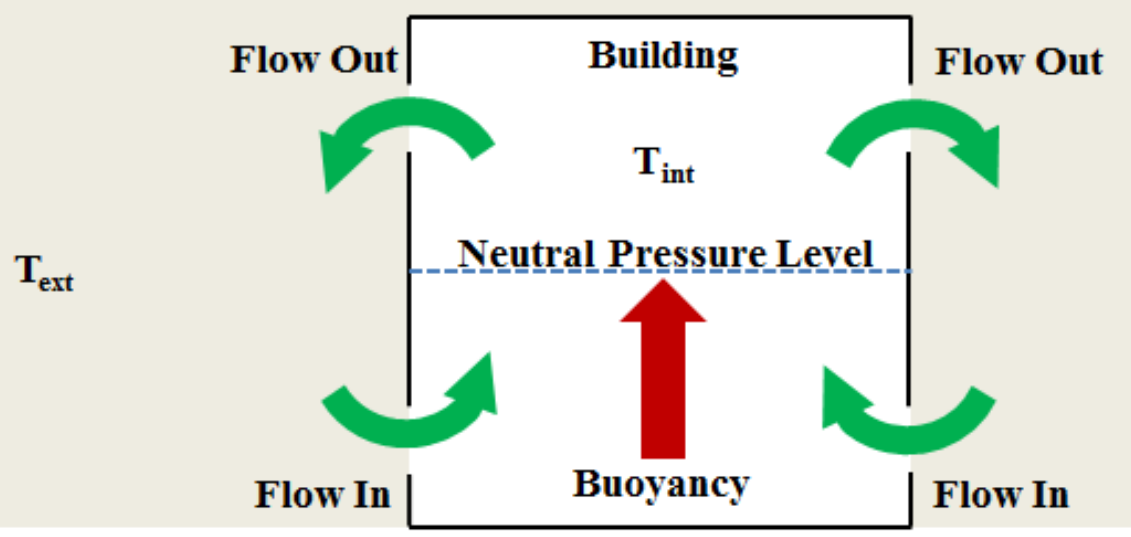

Fig. 2: Schematic representation of pressure differences due to buoyancy effects. 

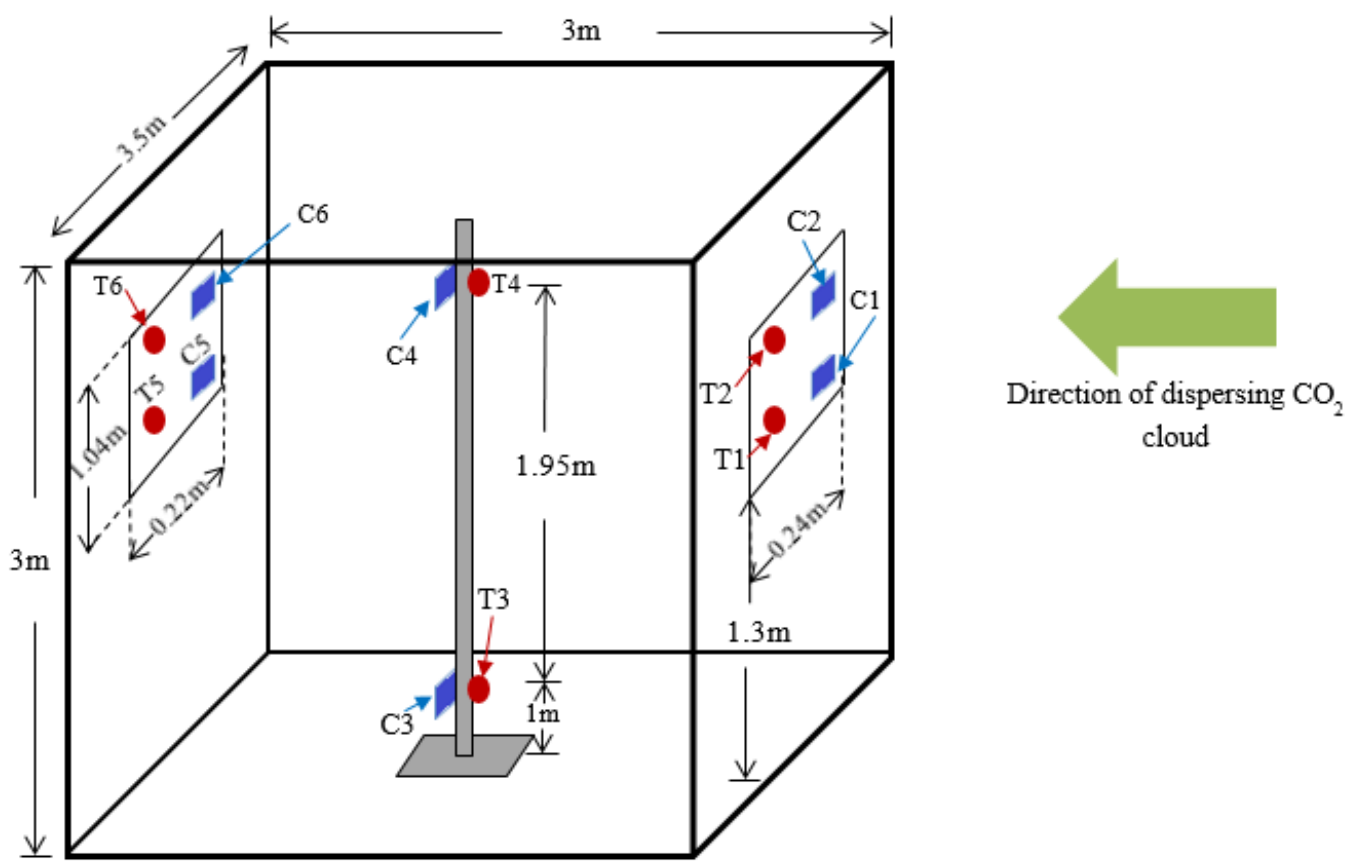

Fig. 3: Schematic diagram of the building and instrumentation system. The prefix ' $C$ ' refers to a concentration measurement sensor and the prefix ' $\mathrm{T}$ ' refers to a temperature sensor. 


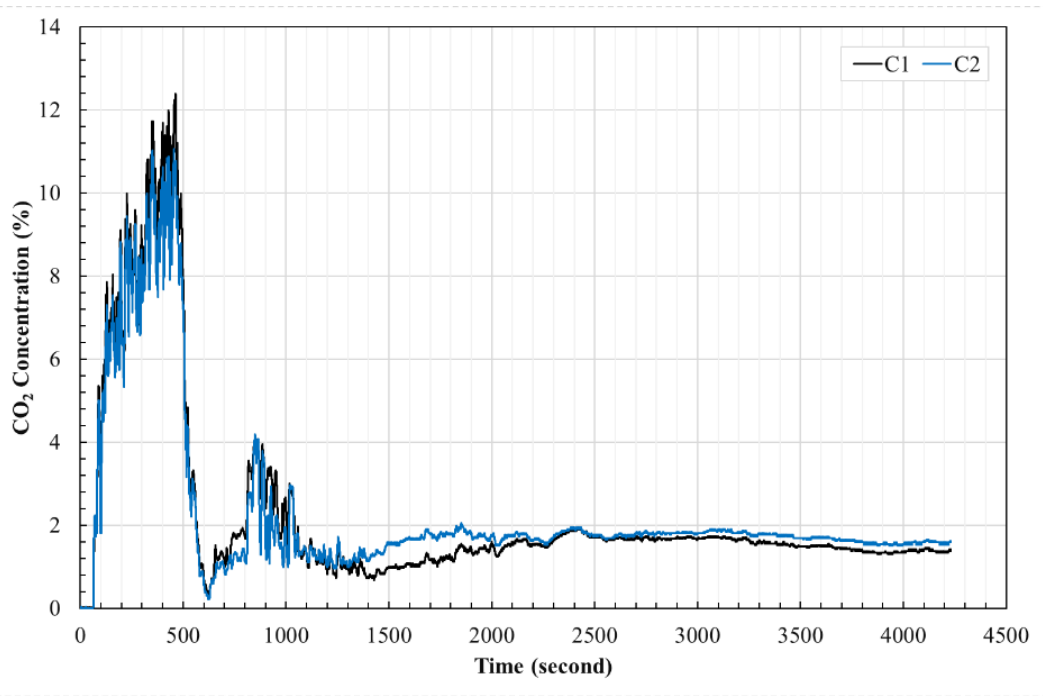

Fig. 4(a)

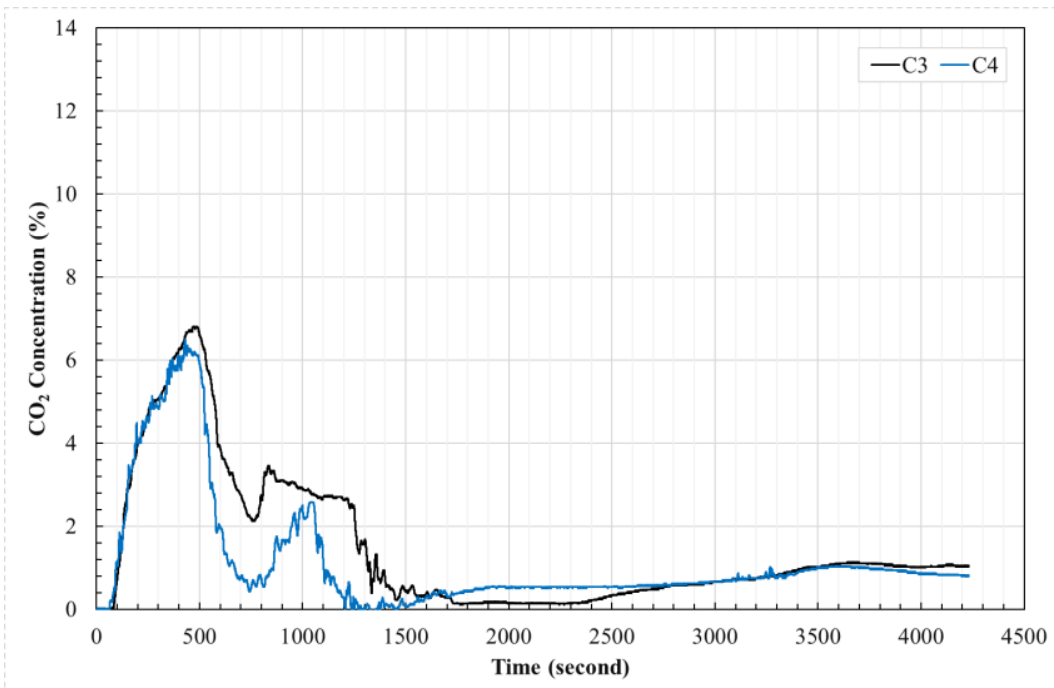

Fig. 4(b)

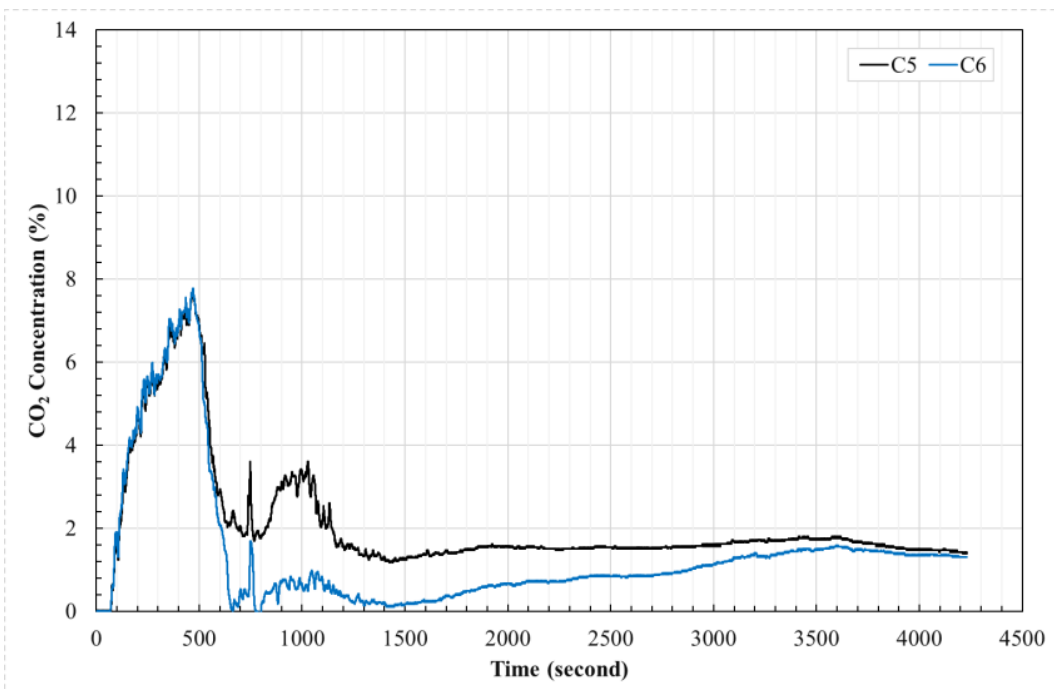

Fig. 4(c)

Fig. 4: Plot of $\mathrm{CO}_{2}$ concentration recorded at: (a) the inlet to the building (sensors $\mathrm{C} 1$ and $\mathrm{C} 2$ in Fig. 1), (b) the centre of the building (sensors $\mathrm{C} 3$ and $\mathrm{C} 4$ in Fig. 1) and (c) the outlet of the building (sensors C5 and C6 in Fig. 1). 


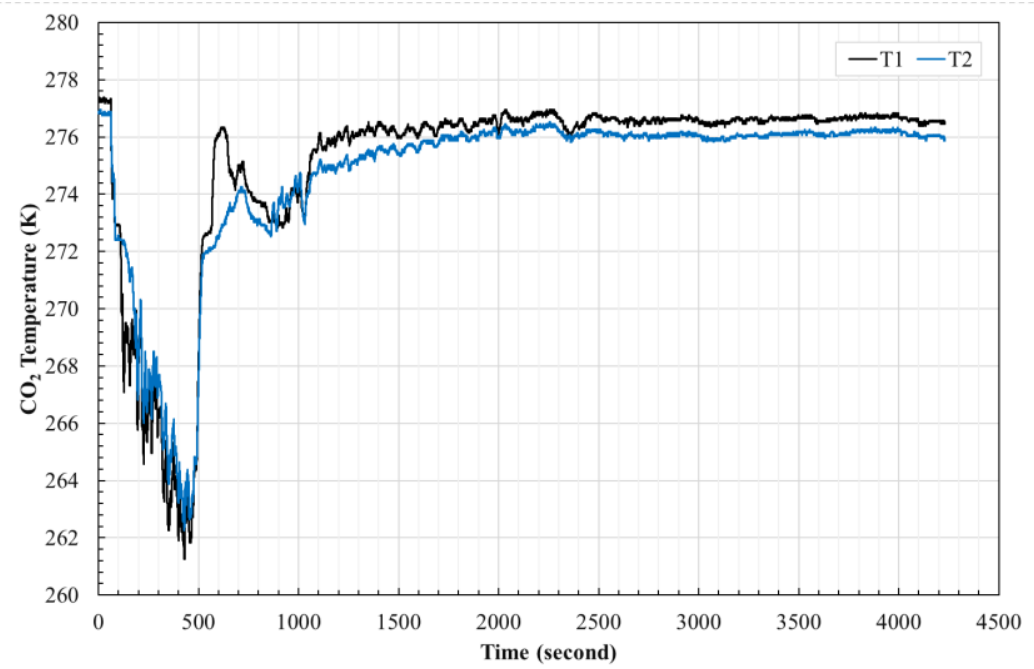

Fig. 5(a)

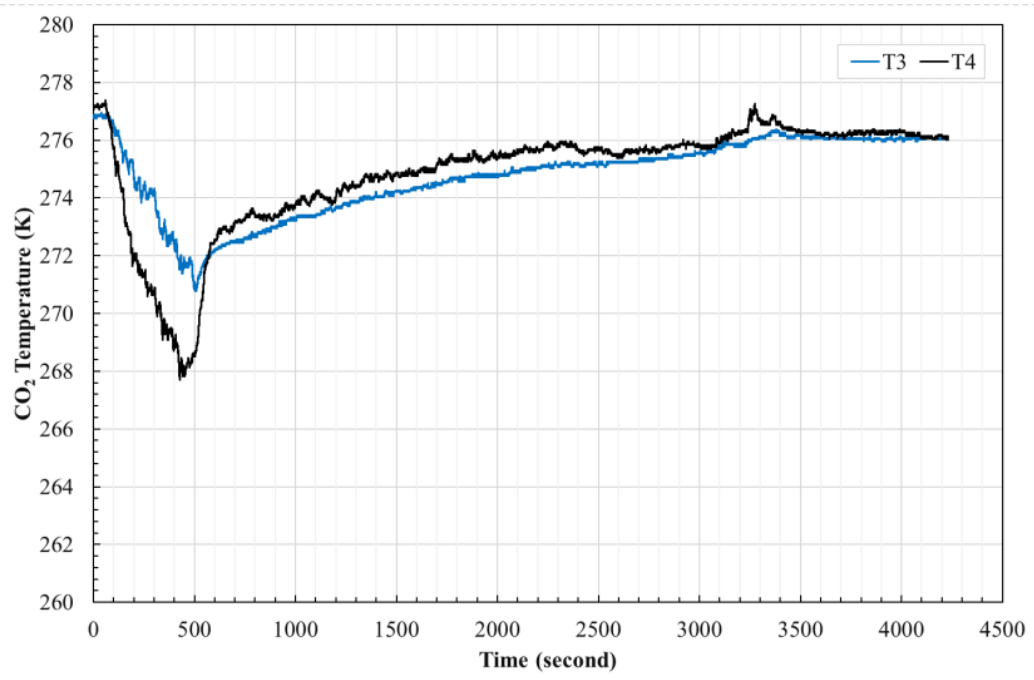

Fig. 5(b)

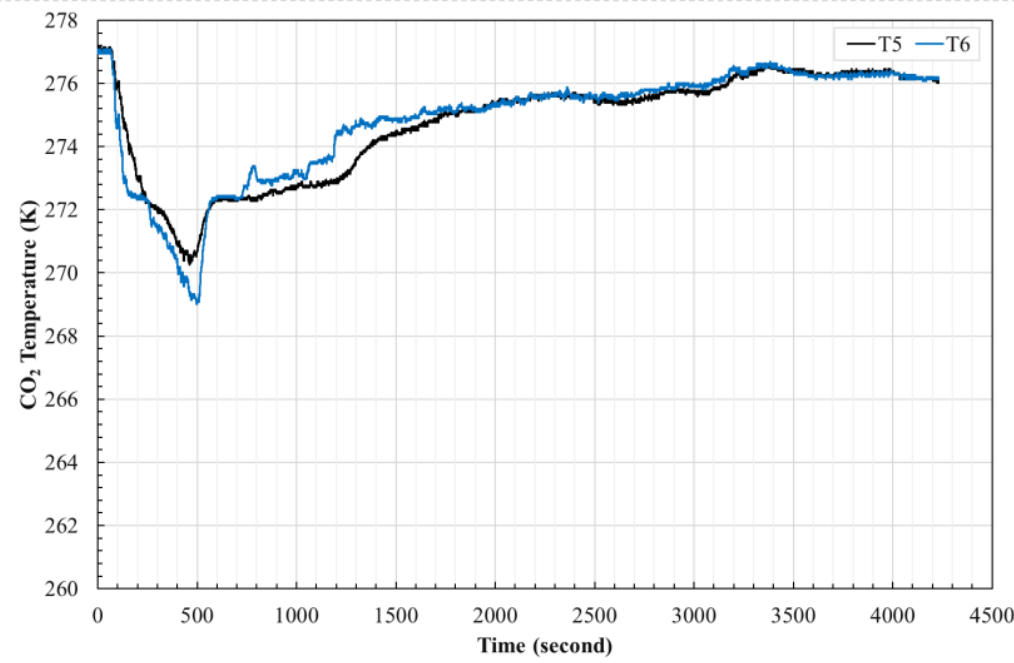

Fig. 5(c)

Fig. 5: Plot of temperature recorded at: (a) the inlet to the building (sensors $\mathrm{T} 1$ and $\mathrm{T} 2$ in Fig. 1), (b) the centre of the building (sensors T3 and T4 in Fig. 1) and (c) the outlet of the building (sensors T5 and T6 in Fig. 1). 


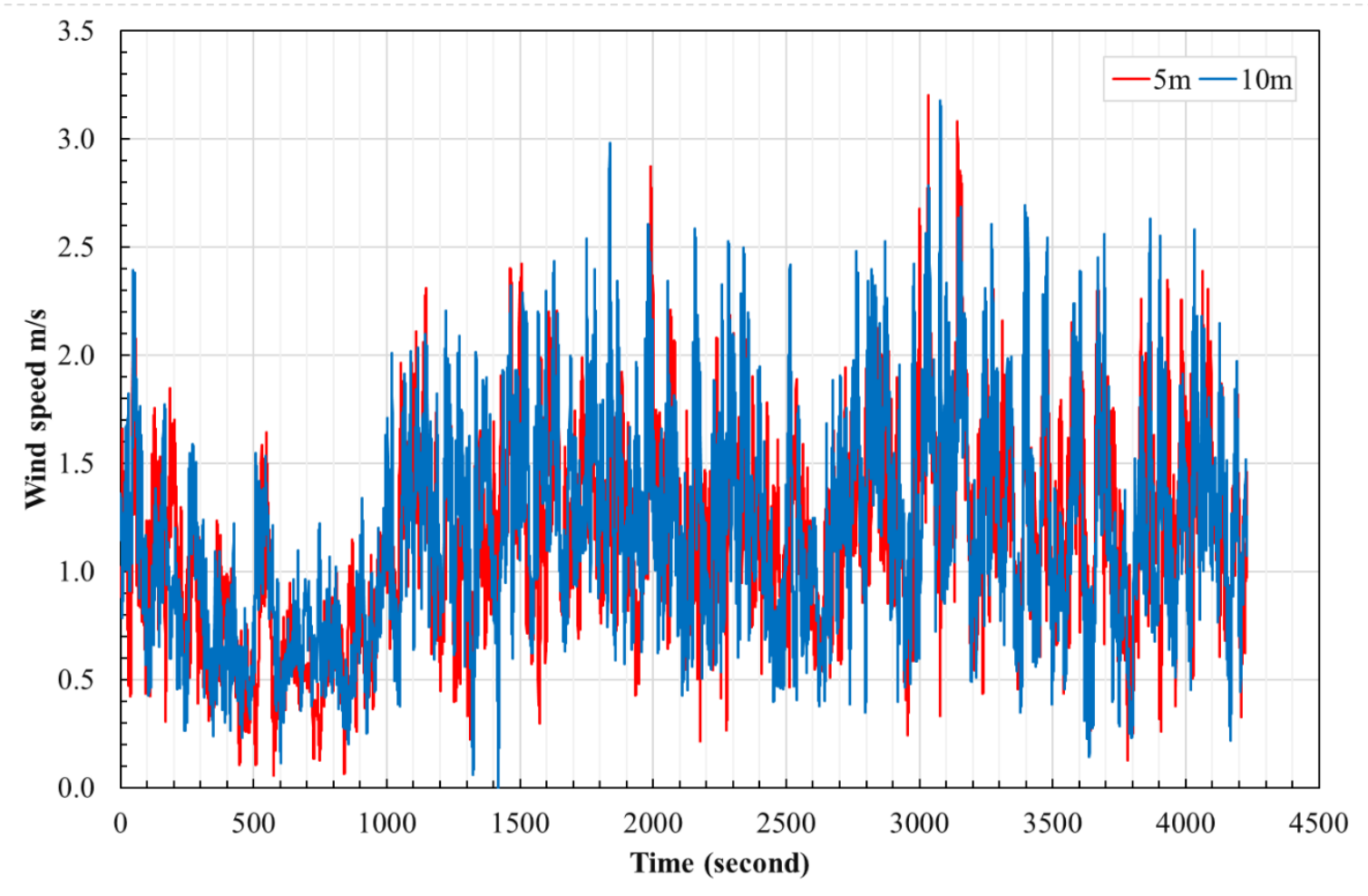

Fig. 6: Plot of recorded wind speed at a height of $5 \mathrm{~m}$ and $10 \mathrm{~m}$ above the ground upstream of the building.
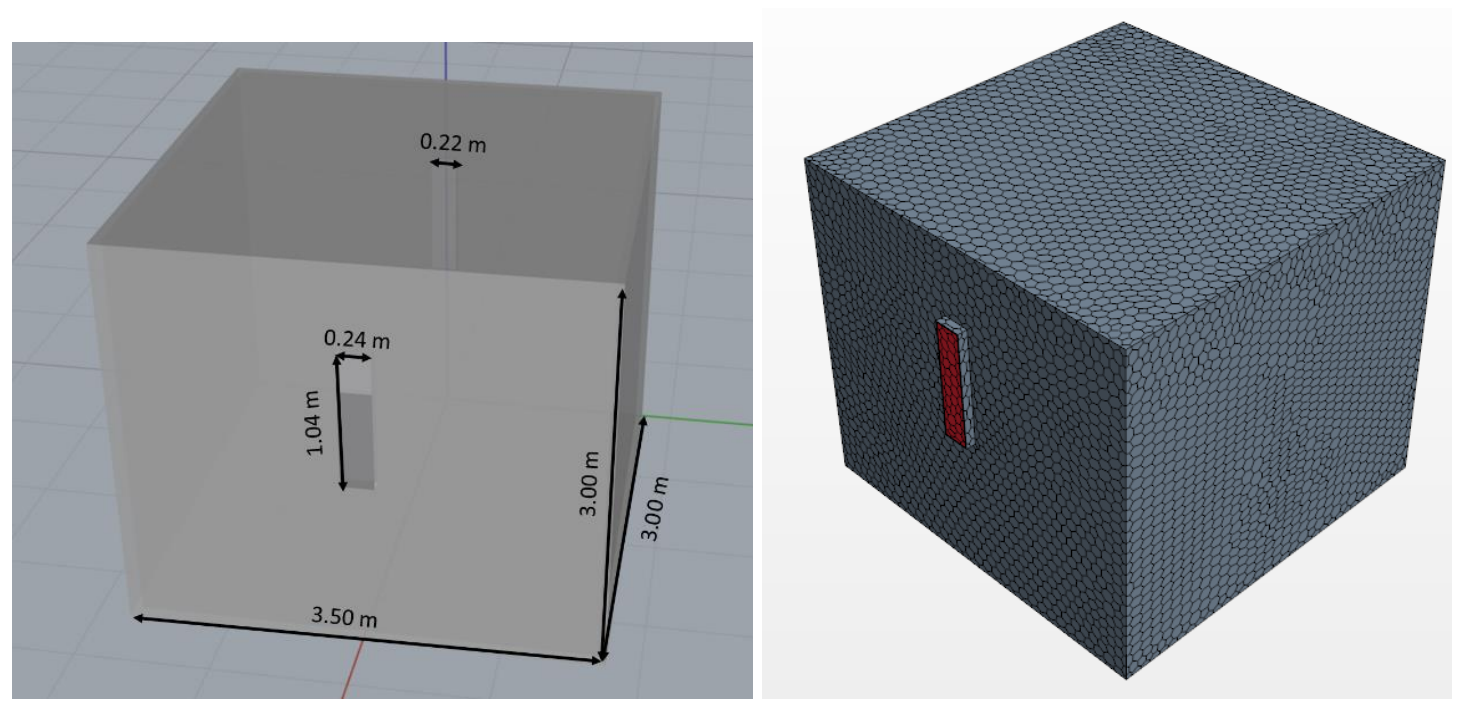

Fig. 7: CAD Model and computational grid used for CFD simulations. 


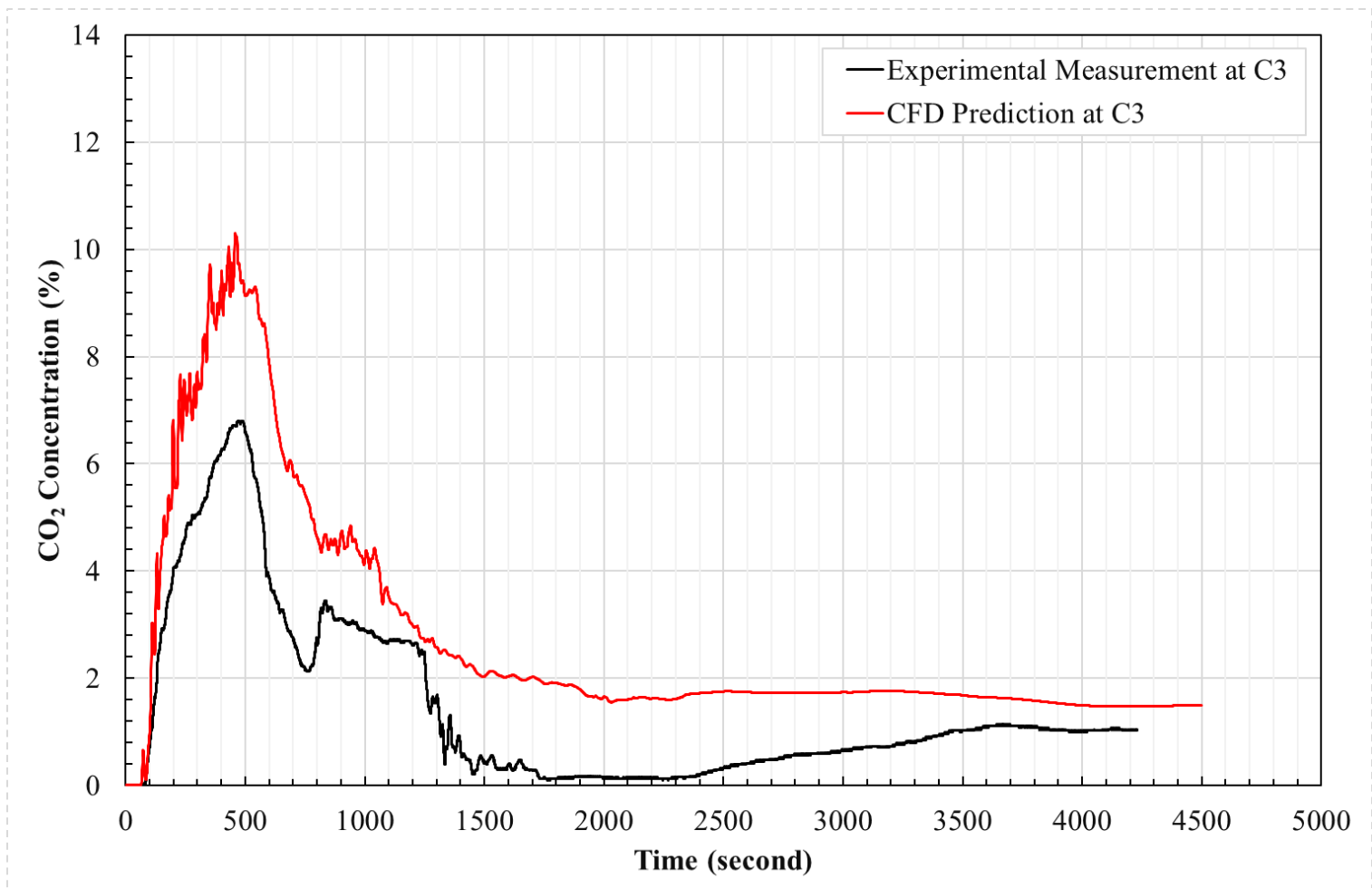

Fig. 8 (a)

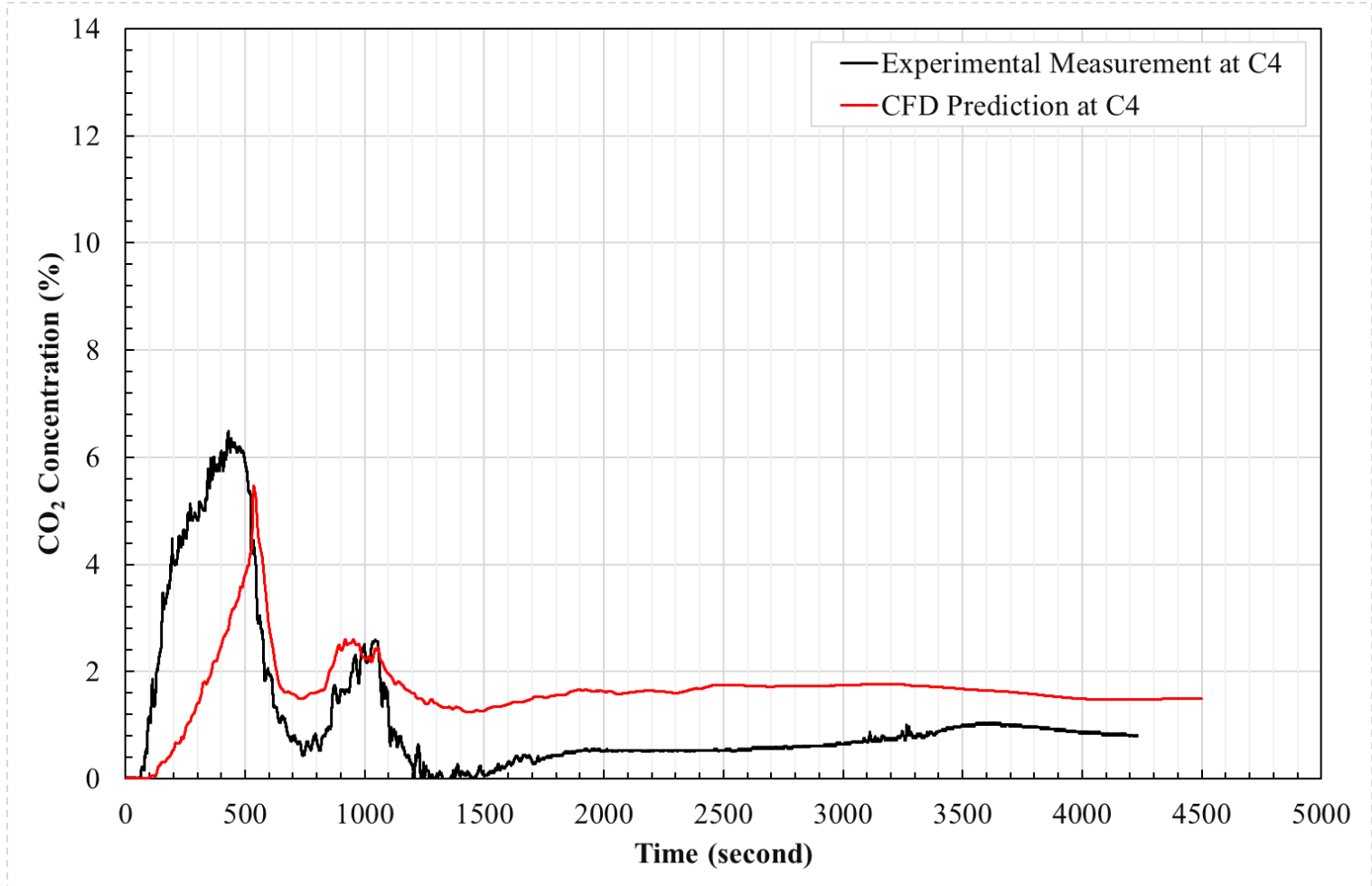

Fig. 8 (b)

Fig. 8: Comparison between experimental measurements and CFD predictions of $\mathrm{CO}_{2}$ concentration at: (a) sensor $\mathrm{C} 3$ and (b) sensor C4. 


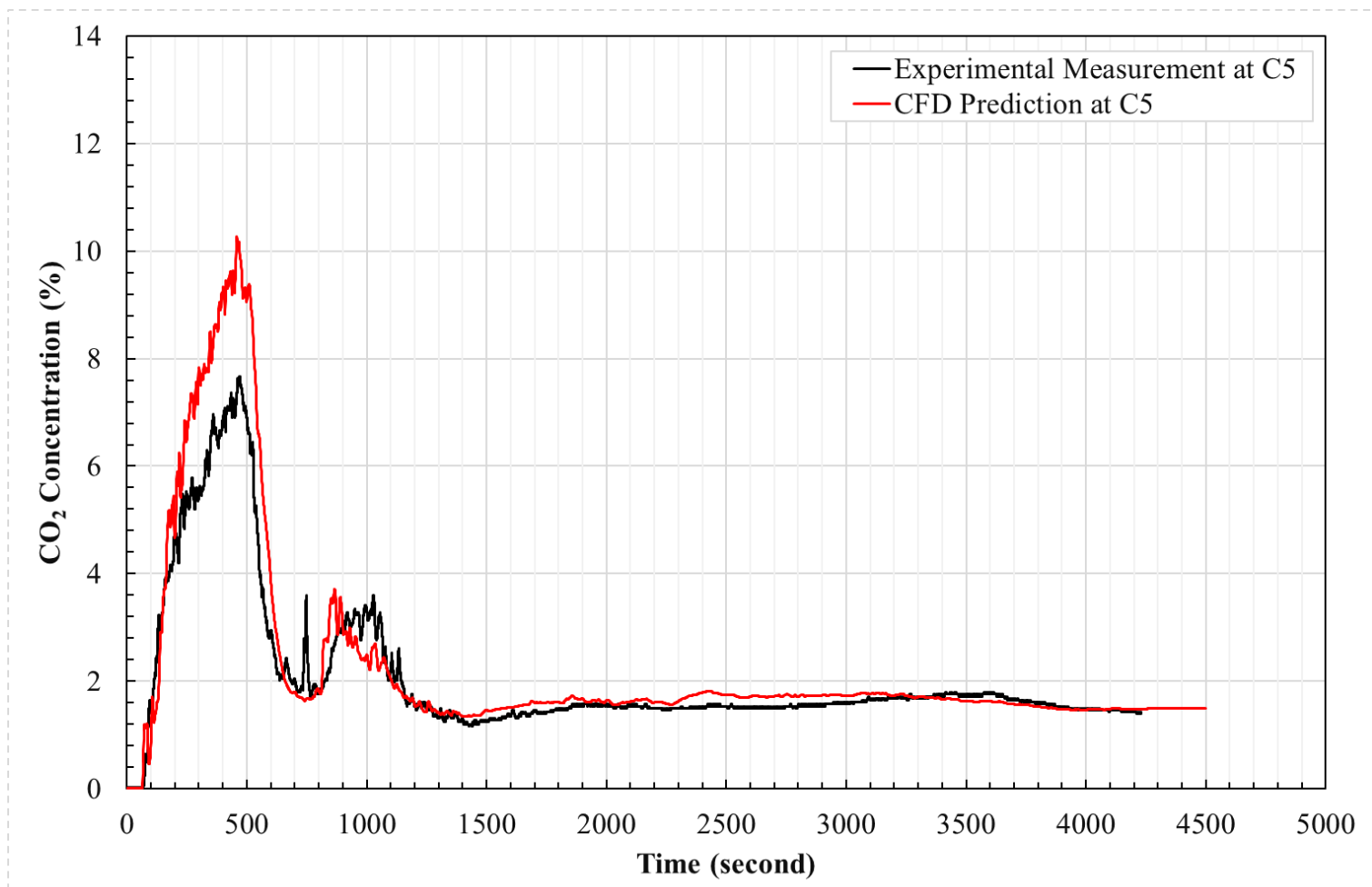

Fig. 9(a)

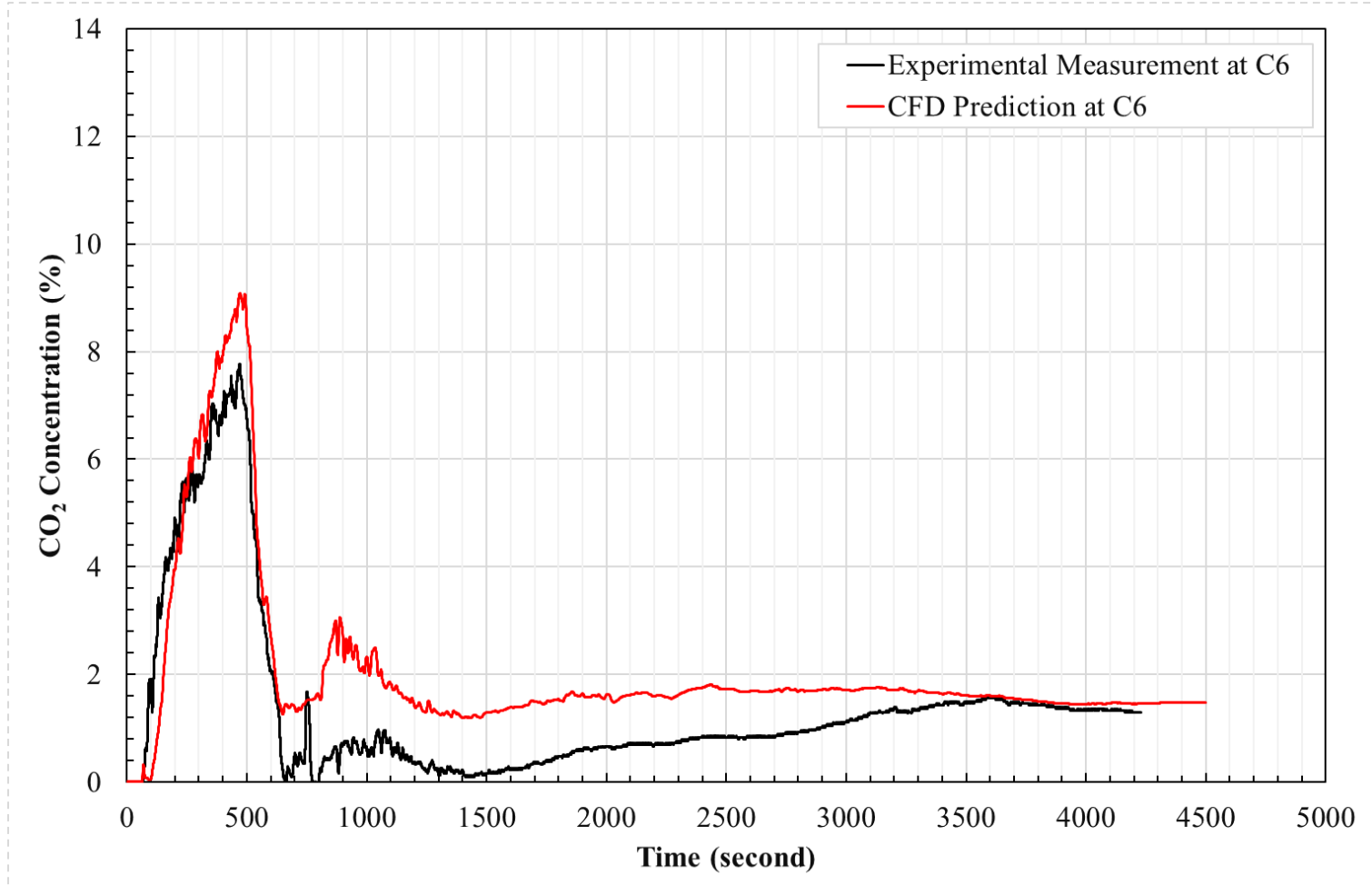

Fig. 9 (b)

Fig. 9: Comparison between experimental measurements and CFD predictions of $\mathrm{CO}_{2}$ concentration at: (a) sensor C5 and (b) sensor C6. 


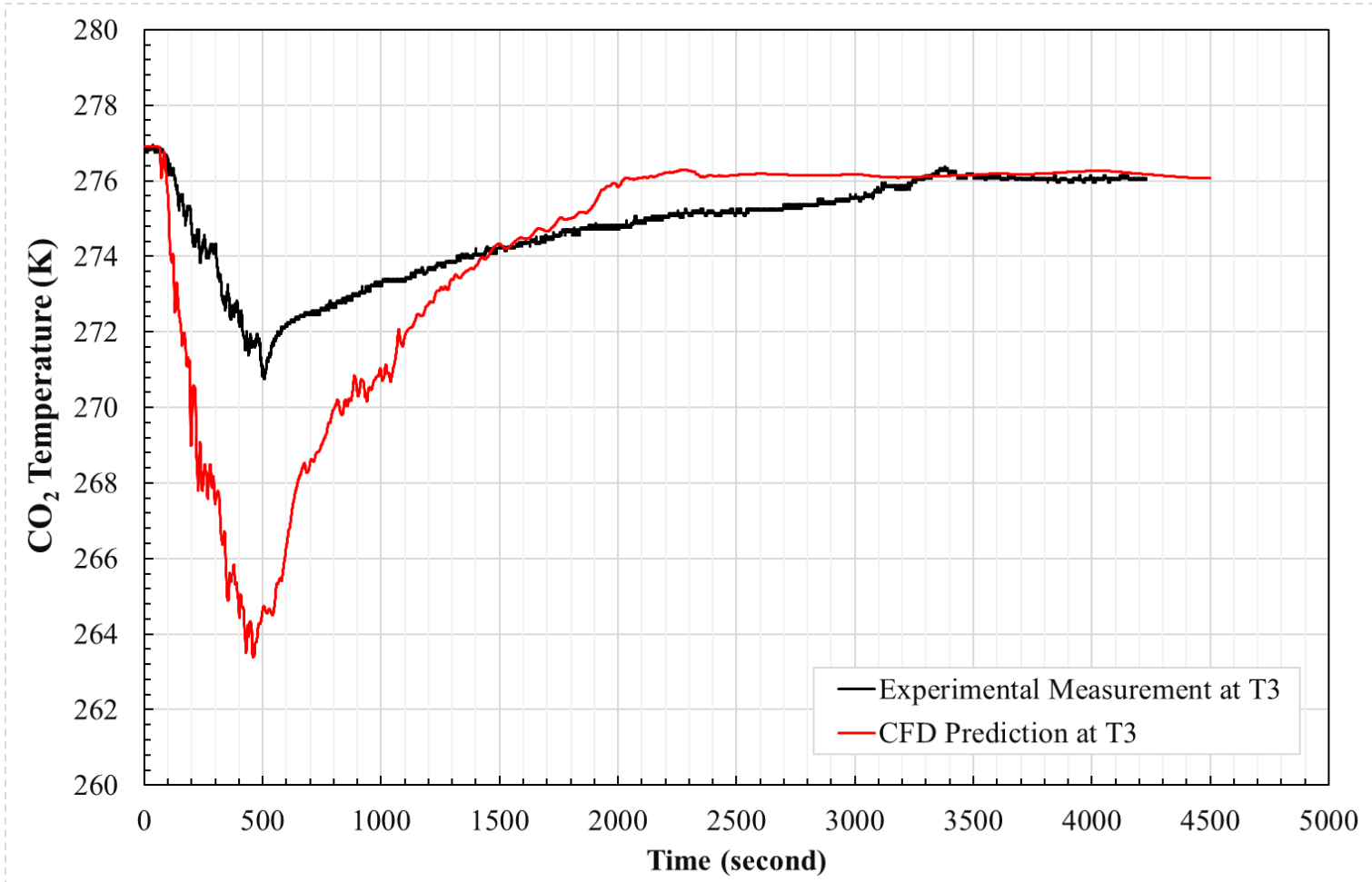

Fig. 10 (a)

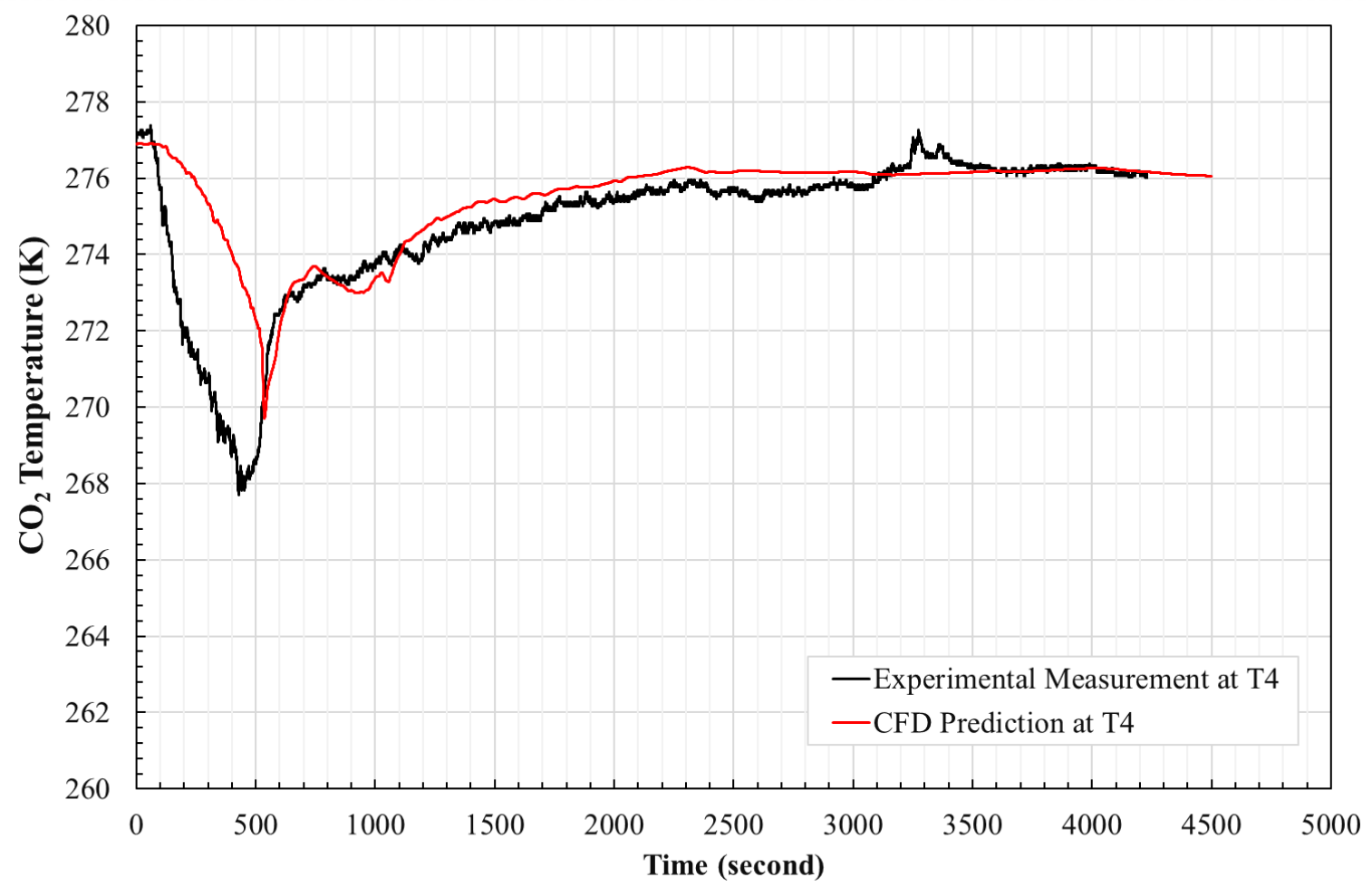

Fig. 10 (b)

Fig. 10: Comparison between experimental measurements and CFD predictions of temperature at: (a) sensor $\mathrm{T} 3$ and (b) sensor $\mathrm{T} 4$. 


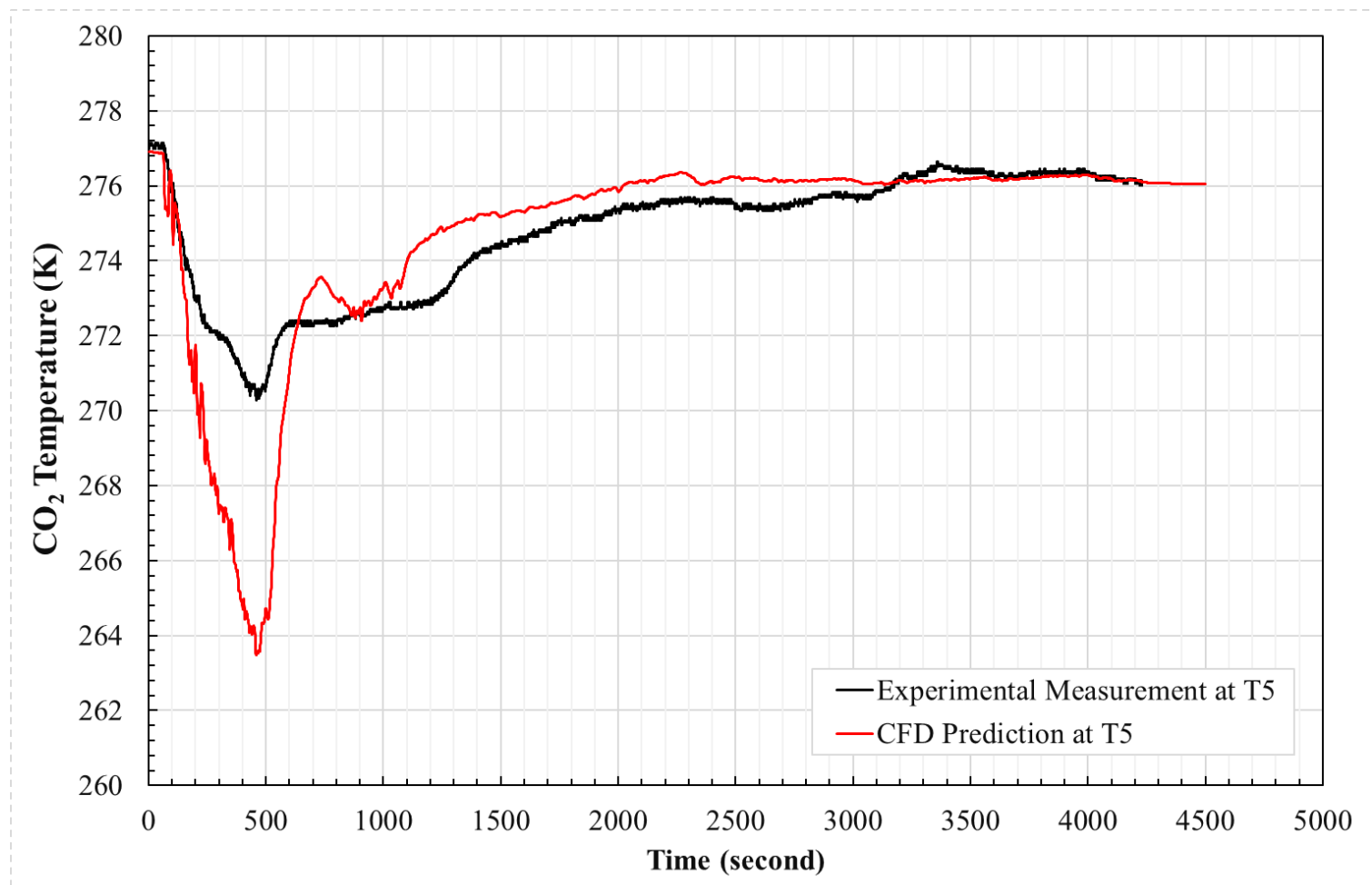

Fig. 11(a)

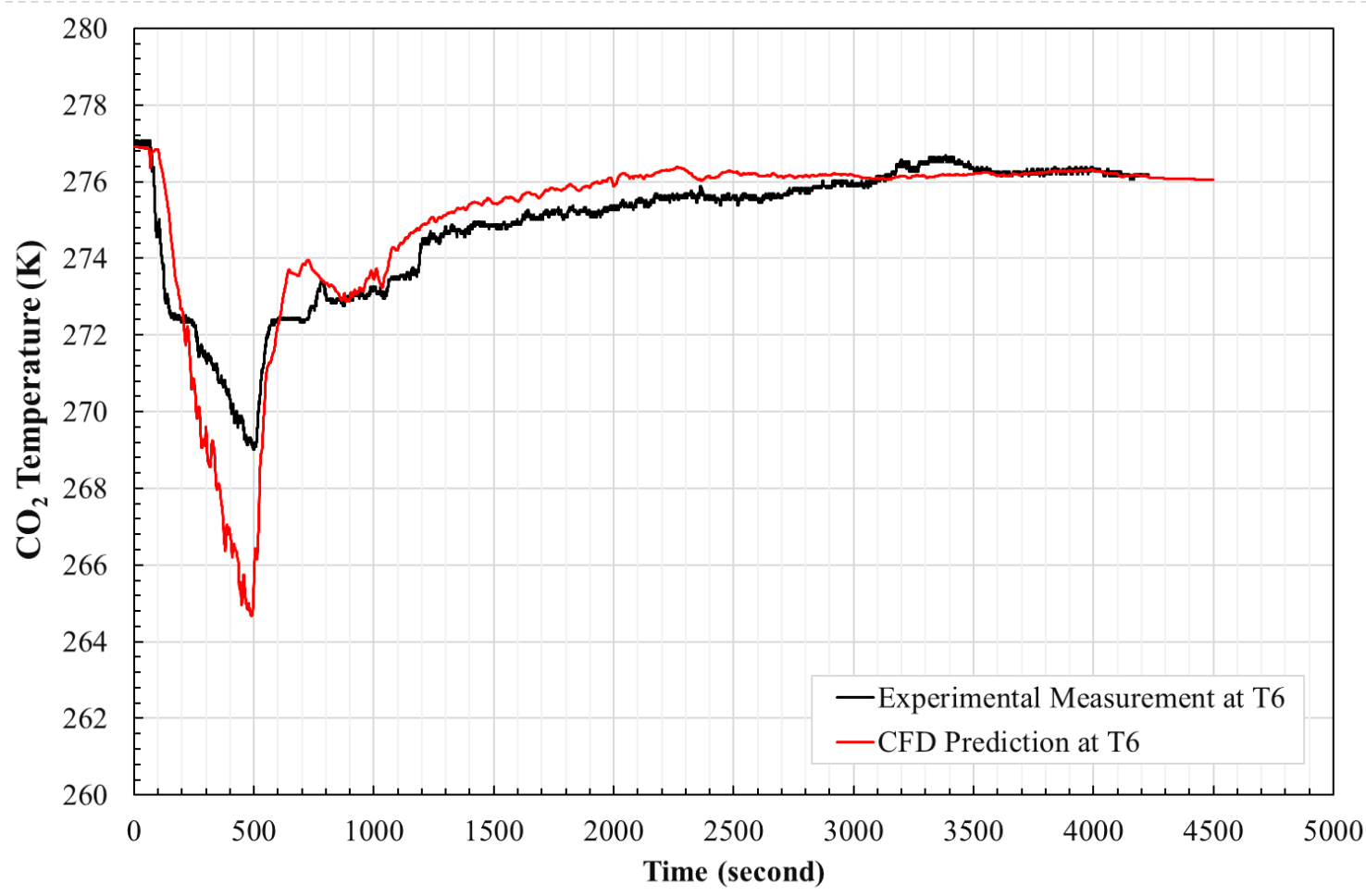

Fig. 11 (b)

Fig. 11: Comparison between experimental measurements and CFD predictions of temperature at: (a) sensor T5 and (b) sensor T6. 


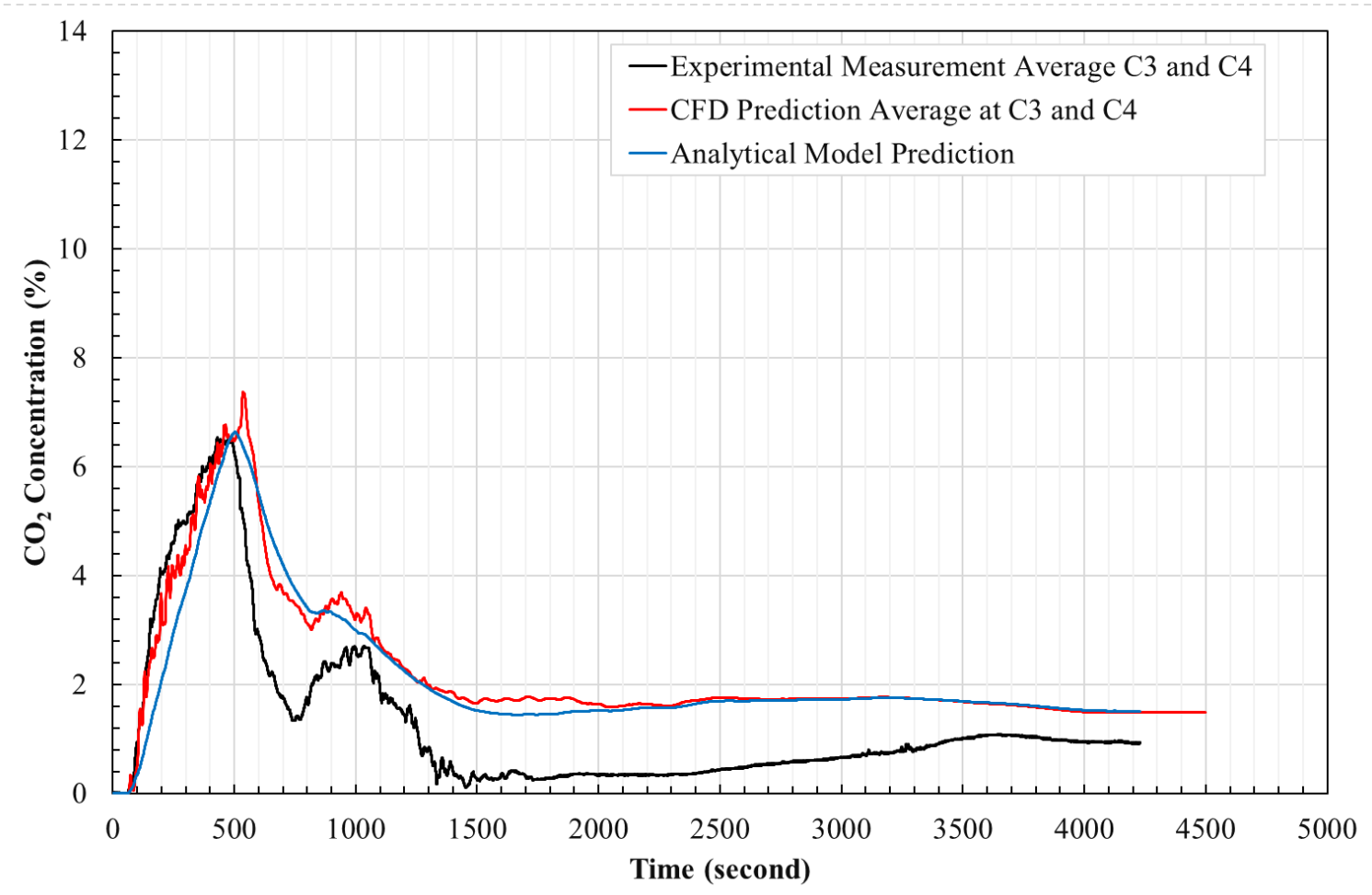

Fig. 12: Comparison between the average of the experimental measurements and CFD predictions of internal $\mathrm{CO}_{2}$ concentration at sensors $\mathrm{C} 3$ and $\mathrm{C} 4$ with the analytical model predictions.

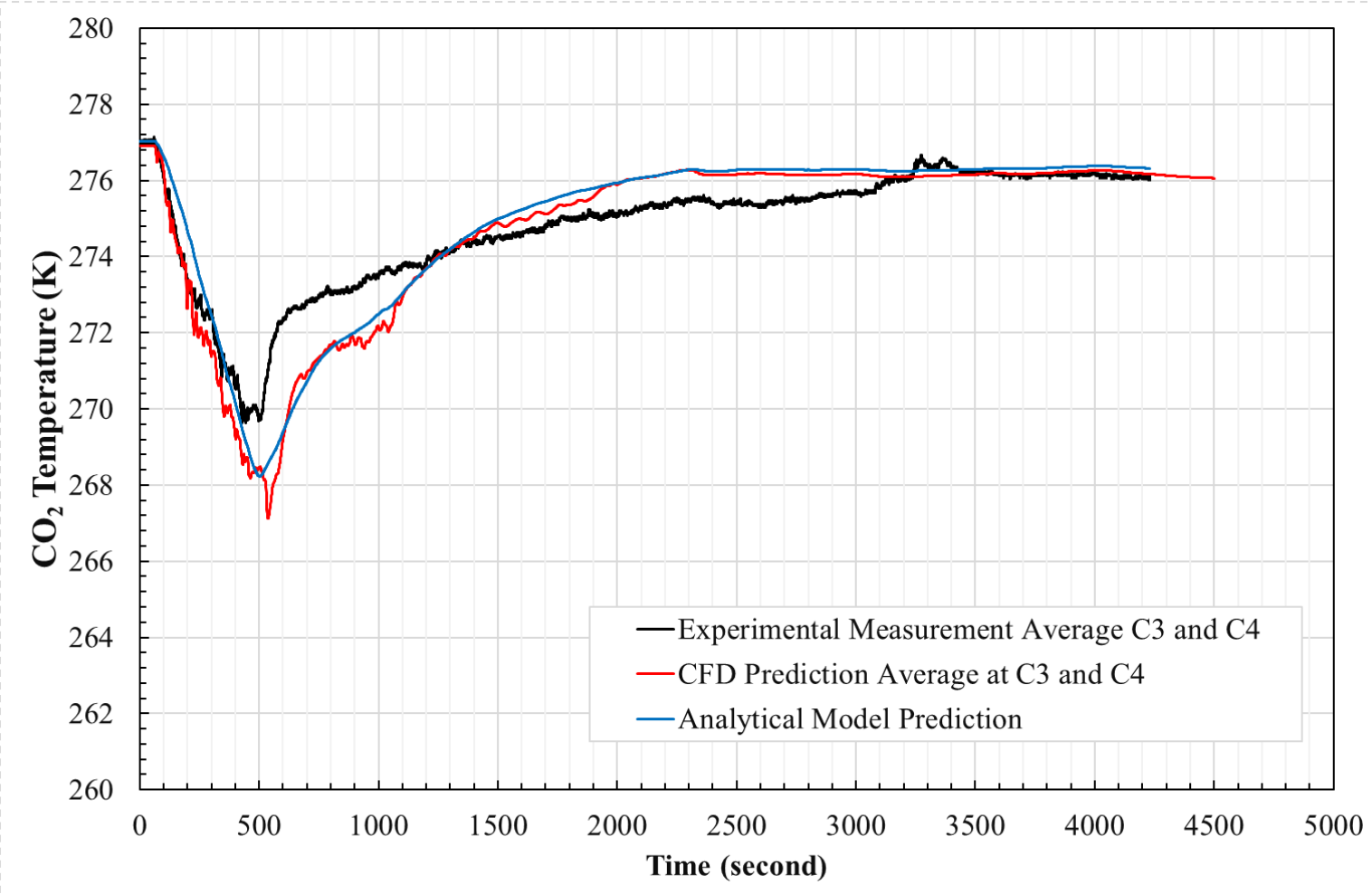

Fig. 13: Comparison between the average of the experimental measurements and CFD predictions of internal temperature at sensors $\mathrm{T} 3$ and $\mathrm{T} 4$ with the analytical model predictions. 


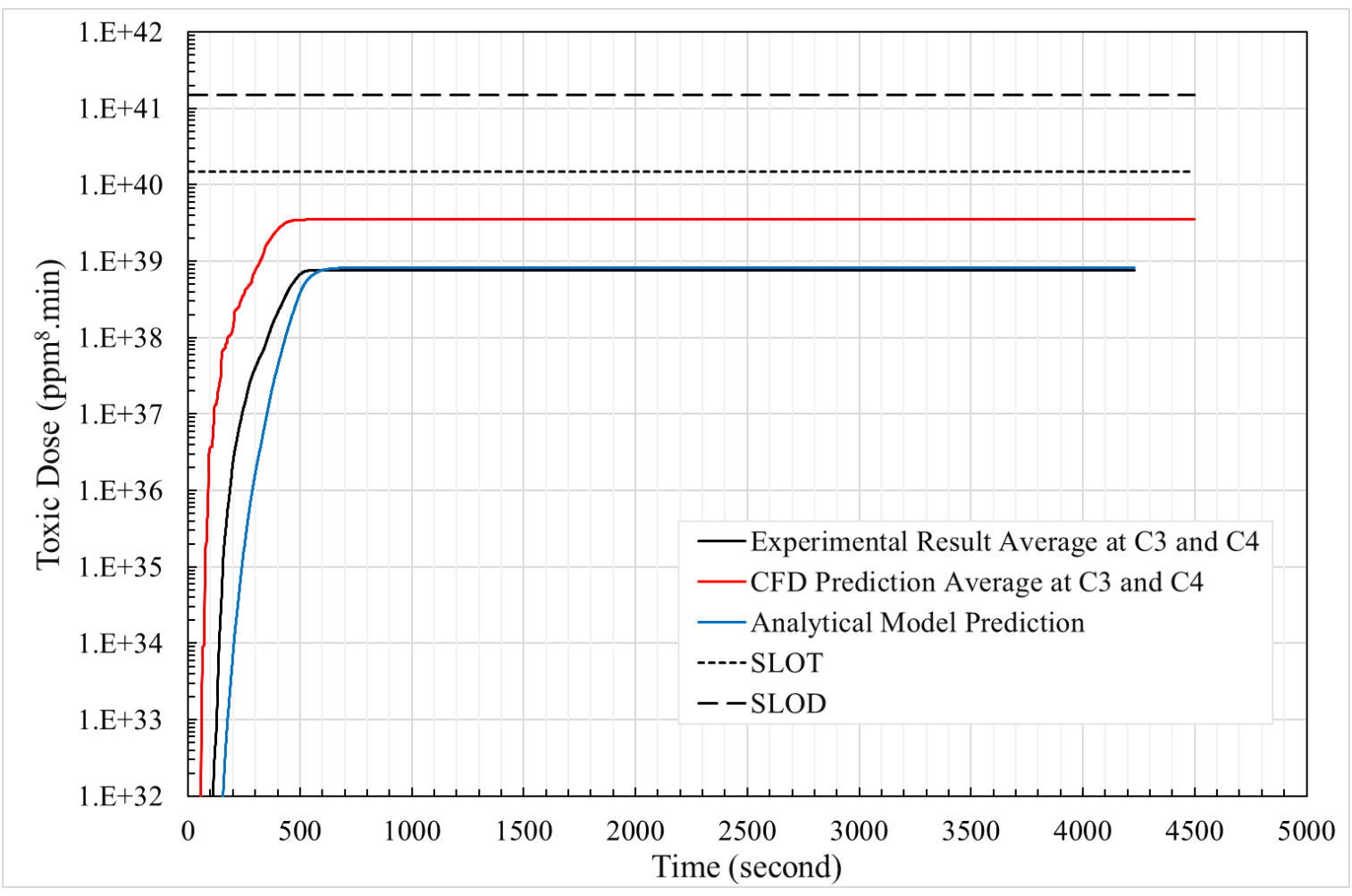

Fig. 14. Comparison between the toxic dose calculated from experimental data, the predicted toxic dose with CFD, both averaged at the sensor locations $\mathrm{C} 3$ and $\mathrm{C} 4$, and the toxic dose profile obtained with analytical model. The SLOT and SLOD are also indicated.

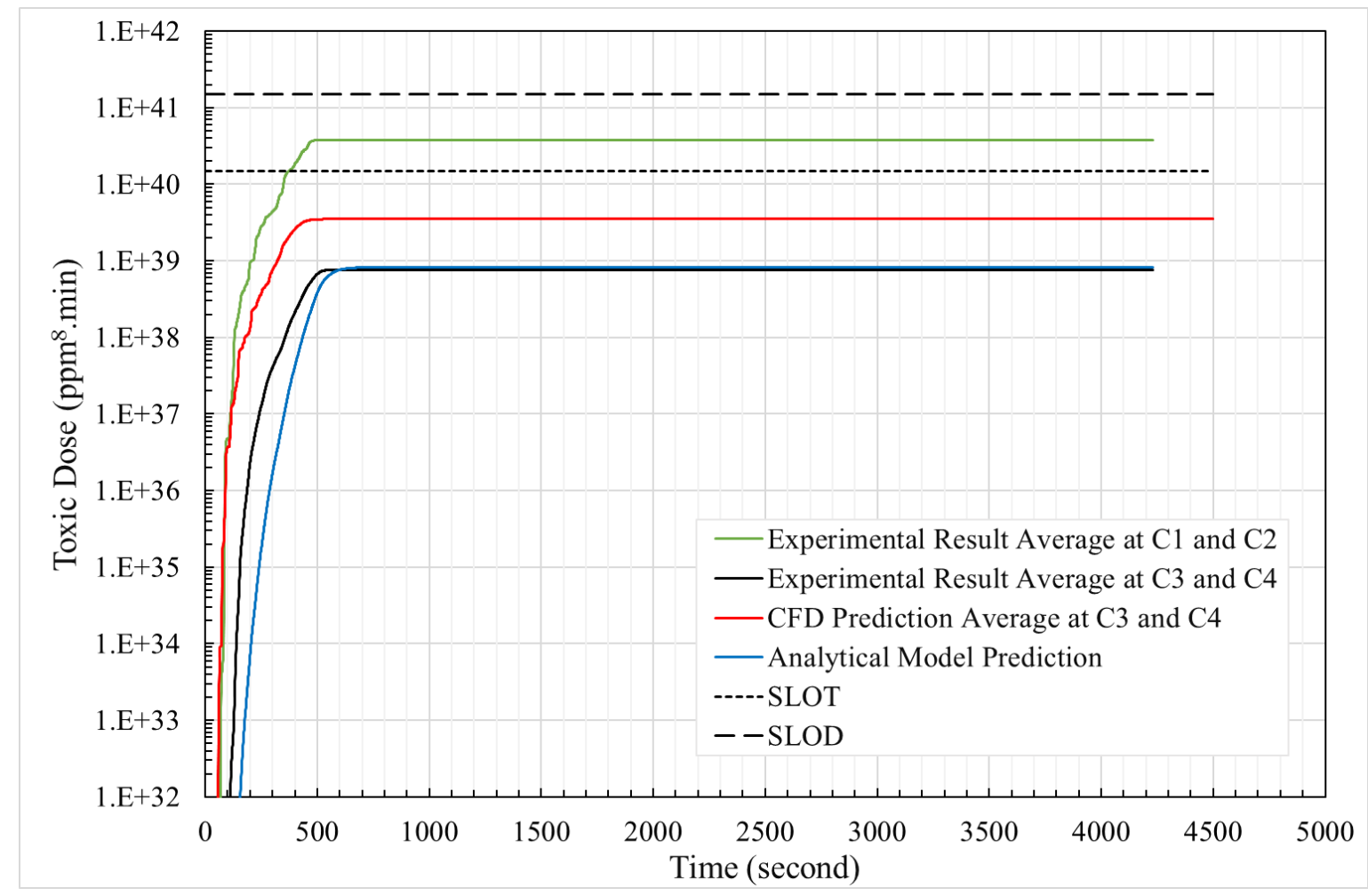

Fig. 15. Comparison between the toxic dose calculated from the experimental data averaged at the inlet sensors ( $\mathrm{C} 1$ and $\mathrm{C} 2$ ) and the internal sensors ( $\mathrm{C} 3$ and $\mathrm{C} 4)$ 